\title{
SMART 2013: Lessons learned from the international benchmark about the seismic margin assessment of nuclear RC buildings
}

\author{
Benjamin Richard ${ }^{\mathrm{a}, *}$, François Voldoire ${ }^{\mathrm{b}, \mathrm{c}}$, Maxime Fontan ${ }^{\mathrm{d}}$, Jacky Mazars ${ }^{\mathrm{d}, \mathrm{e}}$, Thierry Chaudat $^{\mathrm{a}}$, \\ Salim Abouri ${ }^{\mathrm{f}}$, Nicolas Bonfils ${ }^{\mathrm{f}}$
}

${ }^{a}$ DEN - Service d'Etudes Mécaniques et Thermiques (SEMT), CEA, Université Paris-Saclay, F-91191 Gif-sur-Yvette, France

${ }^{\mathrm{b}}$ EDF, R\&D Department, 7 bld. Gaspard Monge, F-91120 Palaiseau, France

${ }^{\mathrm{c}}$ Institute of Mechanical Sciences and Industrial Applications, EDF-CNRS-CEA-ENSTA UMR 9219, 7 bld. Gaspard Monge, F-91120 Palaiseau, France

d OXAND-France, 49 Avenue Franklin Roosevelt, F-77210 Avon, France

e Univ. Grenoble Alpes, CNRS, Grenoble INP, 3SR, F-38000 Grenoble, France

${ }^{\mathrm{f}}$ EDF, SEPTEN, Dynamic and Earthquake Engineering Group, 19 rue Pierre Bourdeix, F-69007 Lyon, France

In this paper, the main findings and conclusions drawn from the second international benchmark named SMART 2013 and jointly organized by the French Sustainable Energies and Atomic Energy Commission (CEA) and Electricité De France (EDF) within the framework of a wide research program entitled "Seismic design and bestestimate Methods Assessment for Reinforced concrete buildings subjected to Torsion and nonlinear effects" (SMART) are presented. A 1:4-scaled reinforced concrete (RC) specimen, representing a part of a nuclear auxiliary building and designed according to French guidelines for a PGA level equal to $0.2 \mathrm{~g}$, was subjected to shaking table tests; results of this experimental campaign are used as reference data for this benchmark. The input ground motions considered in the seismic loading sequence are mainly natural bi-axial signals (main shock and aftershock) recorded during the Northridge earthquake that took place in California, USA in 1994 and have a PGA (Peak Ground Acceleration) about $1.8 \mathrm{~g}$. These high-intensity seismic loadings allow assessing the relevancy of nonlinear numerical models when they have to deal with strong nonlinearities due to concrete cracking. The results produced by the 42 teams which participated in the international benchmark show that (i) the dynamic behavior of the specimen is well captured when dealing with the design level, (ii) the displacement are underestimated when dealing with the beyond design behavior, (iii) the peak frequency shifts are well captured and (iv) the damaging effect of the Northridge aftershock is almost null. Last, seismic safety margins of the specimen are quantified by two mechanical indicators; the results confirm the fact that the RC specimen which was designed according to the codes applicable in the French nuclear industry, exhibits noticeable good performance level regarding collapse prevention.

\section{Introduction}

\subsection{Background}

When dealing with reinforced concrete (RC) structures for which the main function is to ensure the energy production, a specific attention is paid to assess (new buildings) or reassess (existing buildings) their safety level. The case of nuclear power plants (NPPs) is highly monitored in order to anticipate, manage and, ideally, cancel the consequences and the effects that would be caused by an accidental event. When designing the structure of such specific buildings, one can observe a trend which lies in considering a lateral force resisting system
(LFRS) based on the combination of shear walls and beams. The reason for this choice is mainly due to the fact that this design strategy tries to combine the dissipative and ductility properties of frame structure with the stiff character of purely wall based structures. The story-drifts can be controlled in the lower levels of the structure because of the stiff nature of RC shear walls. On the contrary, the frames increase the dissipative capability of the whole building that leads to an increase of the displacement response of the structure. When this type of structures is regular or even slightly irregular, a consensus on the confidence level related to the assessment methodologies is nowadays accepted in the international earthquake engineering community. However, the case of highly irregular frame-wall structures needs to be investigated,

\footnotetext{
* Corresponding author.

E-mail address: Benjamin.richard@cea.fr (B. Richard).
} 
especially in the nonlinear behavior range. Indeed, geometric, mass, stiffness, and strength irregularities may lead to three-dimensional effects such as torsion coupled with bending, increasing with the eccentricity between the torsion center and the mass center.

The safety quantification of such complex RC structures and related equipment regarding the seismic risk requires (i) to assess the seismic safety margins defined as the distance between a limit state expressed as a load bearing capacity and a structural response, (ii) to estimate with an acceptable confidence level the floor response spectra (FRS) useful for equipment seismic reassessment and (iii) to take into account uncertainties related to the input ground motions and to the input material parameters used to calibrate probabilistic structural models. Therefore, numerical analyses should be carried out to estimate as best as possible the responses of a given structure considering extreme seismic loadings for which the intensity measure (IM) overcomes the ones required at the design stage. In addition, because an accurate knowledge of the beyond-design dynamic behavior of the structure is needed to quantify the seismic safety margins, it is also needed to use nonlinear laws to describe the dissipative mechanisms related to the constitutive materials. These dynamic assessment methods are known as "best-estimate approaches" and aim at describing as accurately as possible the physics involved in the degradation process of the structure when an extreme seismic scenario occurs. Furthermore, the relevancy of advanced nonlinear models is not only related to the material parameters to be considered but also to the variability of the input ground motion used to perform the structural assessment. Material parameters and input ground motions are all subjected to uncertainties that should be taken into account. From the aforementioned discussion, it is obvious that improvements in the fields of nonlinear modeling as well as uncertainties modeling propagation are research fields of primary importance for the earthquake engineering community.

The past decades were marked up by major events that gathered the earthquake engineering community along the same path of improvements in the research fields of structural dynamics of low span RC shear walls and related assessment methodologies. The former Nuclear Power Engineering Corporation of Japan (NUPEC) organized a similar international benchmark as the one reported in this paper, under the auspices of the Nuclear Energy Agency (NEA) of the Organization of Economic Cooperation and Development (OECD), twenty years ago. The RC structure under consideration was regular and U-shaped with low span shear walls. The main conclusions were that advanced nonlinear dynamic methods still had to be improved, in particular when dealing with overdesign seismic ground motion leading to the structure working close to its ultimate limit state [1-5]. Some years later, between 1996 and 2002, an extensive experimental campaign was conducted in the scope of the CAMUS research program at the French Atomic Energy and Sustainable Energies Commission (CEA). A symmetric in plane five story RC wall $1 / 3$ th scaled mock-up [6,7] was subjected to shaking table tests to improve the knowledge of this type of RC structures [8]. The acquired experimental data were used in two international benchmarks, held in 1998 and in 2003, to assess the predictive capabilities of existing methodologies. It appeared that the seismic safety margins were frequency dependent; this conclusion was confirmed by the related numerical simulations. In 2006, a blind prediction contest on the seismic response of a 7-story full-scale RC building with cantilever structural walls acting as the LFRS was launched by the Network for Earthquake Engineering Simulation (NEES), Portland Cement Association and University of California at San Diego. The objective of that research program was to check the seismic response of RC wall systems designed for lateral forces by means of a displacement-based design methodology to emphasize the interaction between the walls and the slabs [9-14]. To address the complex issue of the safety margins quantification in case of strongly irregular RC structures regarding the seismic risk, a wide research project named Seismic Design and Best-Estimate Methods Assessment for Reinforced Concrete Building Subjected to Torsion and Nonlinear Effects (SMART) started in 2006 by the CEA and Electricité De France (EDF), under the auspices of the International Atomic Energy Agency (IAEA). The first part of this project, named SMART 2008, included both an international benchmark [15] and an experimental campaign [16,17] based on seismic tests carried out on the AZALEE shaking table, as part of the TAMARIS experimental facility operated by the Nuclear Energy Division (NED) of the CEA. A mock-up representing a typical simplified part of an electrical nuclear RC building at the 1/4th scale was designed and built, according to the well-known Cauchy-Froude similitude law. The trapezoidal three-story specimen was composed of three walls with openings forming a U-shape and was designed according to the French current nuclear engineering practice, that means the use of response spectrum method and Eurocode 2 criteria for reinforcement design, at the design earthquake level. Seismic inputs of increasing intensity up to a maximum Peak Ground Acceleration (PGA) of $0.9 \mathrm{~g}$ were applied to the mock-up; these synthetic accelerograms were generated from the design spectrum. Research revealed the existence of seismic safety margins. As seismic safety margins quantification needs to consider structural response indicators, several indicators were analyzed [15]. Nevertheless, two key points were identified as potential sources of improvements. The first one was related to the choice of the input ground motions, which induced a progressive damage of the RC specimen that is not fully representative of a natural seismic scenario and the second one was related to the way of controlling the boundary conditions, in particular at the interface between the shaking table and the RC mock-up.

Faced with the success of the SMART 2008 project and given the interest of the earthquake engineering community in addressing this complex issue, CEA and EDF decided in 2011 to extend the SMART project by starting a second part, named SMART 2013, with the aim of improving the aforementioned aspects. A new experimental campaign including shaking table seismic tests was carried out in July 2013 with the AZALEE shaking table, on a RC specimen having a similar shape as the one tested during SMART 2008. Pictures of the SMART 2013 RC specimen are shown in Fig. 1.a and 1.b. More precisely, the SMART 2013 RC specimen is a 1/4th scaled mock-up representing a part of a nuclear auxiliary building. It was designed in 2010 according to the French practice and guidelines prevailing in 1998 [18] and 2006 [19]. The design PGA is equal to $0.2 \mathrm{~g}$. The only difference between the SMART 2008 specimen with the one studied in SMART 2013 is related to the design of the foundation. This part of the specimen has been reinforced in order to improve the specimen/shaking table connection. A detailed description of the design assumptions can be found out from [20].

The seismic bi-axial loadings were based on an extreme seismic scenario composed of three main sequences: the design signal (synthetic - PGA $=0.2 \mathrm{~g}$ ), a main shock (natural - PGA $=1.78 \mathrm{~g}$ ) and the first aftershock (natural - PGA $=0.37 \mathrm{~g}$ ), both recorded at the Tarzana Cedar Hill monitoring station, during the Northridge earthquake that occurred in California, USA, in 1994 [21]. Such high PGA levels were chosen to examine the beyond design behavior of the SMART 2013 RC specimen. In addition, the boundary conditions at the interface between the SMART 2013 RC mock-up and the shaking table were particularly well controlled and specific data related to the shaking table dynamic behavior itself were also acquired. The experimental measurements were used in a second international benchmark devoted to the assessment of the beyond design responses of the RC mock-up subjected to the aforementioned seismic scenario and to the quantification of its vulnerability within a probabilistic framework.

\subsection{SMART 2013 international benchmark content}

The SMART 2013 international benchmark was organized between February 2012 and September 2014 and was concluded by an international workshop which took place in Saclay, France from 25th to 27th November 2014 [22]. 42 participating teams from all over the 


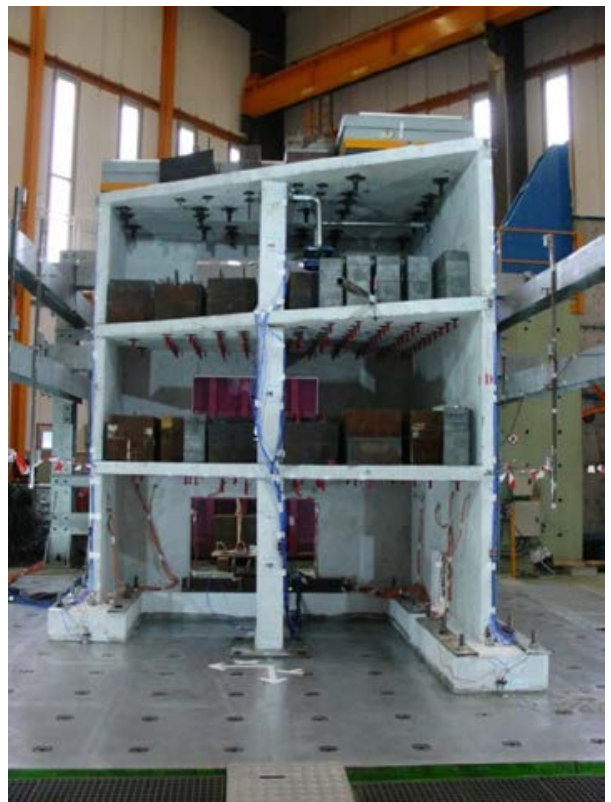

(a) Front view

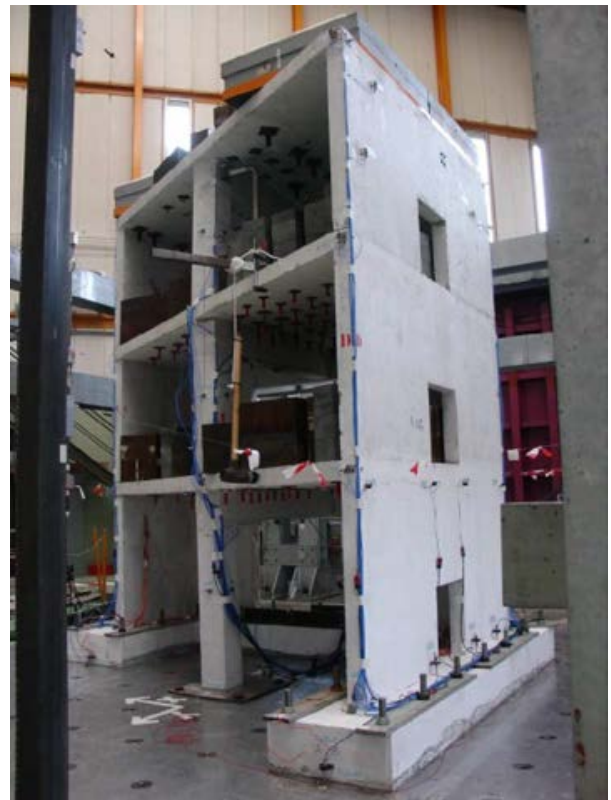

(b) Lateral view

Fig. 1. Pictures of SMART 2013 RC specimen.

world were registered. The list of the participants is provided in Appendix A, including the parts of the benchmark they were involved in.

The objectives of the benchmark were (i) to assess the capabilities of advanced best-estimate methods in predicting the seismic response of a complex RC specimen, subjected to beyond design dynamic loadings that may occur in case of extreme seismic events; in particular the capabilities of nonlinear numerical models to capture the structural damage from a natural seismic scenario consisting of a main shock and an aftershock in a satisfactory way for a given magnitude/distance couple, (ii) to improve the use of probabilistic methodologies addressing random and epistemic uncertainties to estimate the fragility curves, (iii) to share about seismic assessment methodologies and attempt to build a consensus within the international seismic engineering community. To reach these objectives, the results from the SMART 2013 experimental campaign were extensively used.

The SMART 2013 international benchmark was composed of four stages. Stage 1 was devoted to the characterization of the numerical models used by all the participating teams. Several data regarding the spatial/time discretization, the time integration algorithms used and the ways of taking the boundary conditions into account were asked to the participants. A description of the structural model was also required. In order to assess the relevancy of the assumptions considered in the constitutive laws formulations (concrete, steel and steel/concrete interface), a description of the effects taken into account was required. Therefore, each participant was asked to carry out basic static tests considering more or less complex (both monotonic and cyclic) loading paths on a representative volume element (RVE) of concrete, steel and RC. No dynamic loading was considered in stage 1. Stage 2 aimed at calibrating the numerical finite element (FE) structural models in the elastic range. In order to reach this objective, modal analyses considering various boundary conditions and transient analysis were required: modal properties and time history responses at various points. Only two low-intensity seismic loadings, with PGA equal to $0.1 \mathrm{~g}$, were considered: a random signal (run \#6) and a synthetic seismic signal (run \#7) corresponding to $50 \%$ of the design seismic loading in terms of PGA. Both measured seismic inputs and outputs were given to the participants. In order to allow the participants to control the boundary conditions accurately, they were provided with displacements and accelerations time histories measured at the shaking table actuators. In addition, CEA also provided them with a numerical FE model of the AZALEE shaking table accounting for the exact position of the actuators to allow an accurate description of the whole dynamic system (RC specimen and shaking table). In stage 3 , blind nonlinear dynamic computations for medium to high-intensity seismic loading sequences (7 successive seismic motions, with PGA ranging from 0.2 to $1.78 \mathrm{~g}$ ) and corresponding time history responses at various points were asked to the participants. The nonlinear analysis of 7 seismic loadings, 2 being optional, was required. Only the seismic inputs were provided to the participants. The measured outputs were not available when stage 3 was ongoing, this strategy enabled to analyze the predictive capabilities of the assessment methodologies used by the participants. Finally, stage 4 was devoted to a numerical vulnerability analysis of the RC specimen within a probabilistic framework addressing random and epistemic uncertainties. The purpose of this stage was to assess the effect of the type of uncertainties on the fragility curves considering various failure criteria and engineering demand parameters. Two sub-stages were considered. In the first one, the numerical model was assumed to be linear elastic. Participants were free to use their own methodology to compute the fragility curves. In the second sub-stage, participants had to consider nonlinear constitutive laws to describe the energy dissipation and the failure mechanisms. The methodology to compute fragility curves was imposed, assuming a lognormal distribution of the random variables. For all sub-stages, the set of input ground motions was provided.

\subsection{Outline}

This paper aims at presenting the main conclusions and findings from the SMART 2013 international benchmark, emphasizing the assessment of the seismic safety margins of the RC specimen that was studied. To reach this aim, this paper is outlined as follows. In Section 2 , the panel of numerical models developed by the participating teams is presented. In particular, the modeling assumptions related to the nonlinear constitutive laws used are presented. In addition, the results from the calibration stage are also summed up and discussed. Section 3 is devoted to the estimation of the seismic safety margins of the SMART 2013 RC structure. Two indicators are considered in order to describe the structural responses under seismic loadings. The results obtained by the participants are compared with the experimental ones and are 


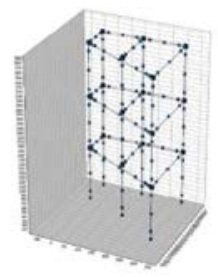

(a) 0D model.

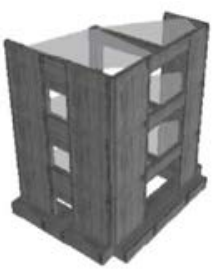

(b) $1 \mathrm{D}$ model.

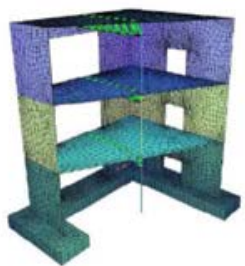

(c) 2D model.

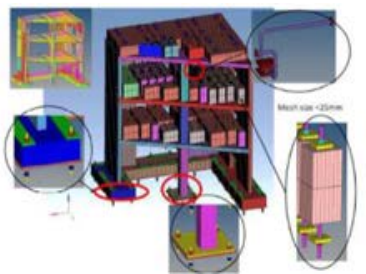

(d) 3D model.

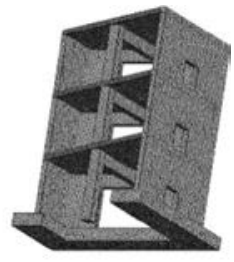

(e) DM model.

Fig. 2. Examples of FE meshes used by the participants.

positioned with respect to different damage thresholds in order to (i) quantify the seismic safety margins of the specimen and (ii) assess the capability of nonlinear models to corroborate the experimental observations under a blind contest. At the end of this section, the results obtained within the framework of stage 4 , dedicated to the vulnerability analysis through fragility curves calculations, are presented and discussed. In Section 4, the conclusions from the SMART 2013 international benchmark are drawn regarding several aspects such as (i) the key assumptions to consider in order to ensure the relevancy of a nonlinear structural model when the assessment of the seismic safety margins is aimed, (ii) the capability of advanced nonlinear FE models to make predictive seismic assessments in case of a strongly irregular RC structure and (iii) the relevancy of the two indexes studied to assess the seismic safety margins.

\section{Modeling assumptions, constitutive laws and initial structural calibration}

In this section, the modeling assumptions made by the participants to deal with the required analyses are presented. The various modeling strategies used are briefly presented before focusing on some local results allowing the characterization of the nonlinear constitutive laws used to describe the material response of steel, concrete, or reinforced concrete. In addition, the ability of the numerical models to describe the seismic response of the specimen under low-level dynamic loading in a satisfactory way is analyzed. The results presented in this section correspond to a part of the ones provided by the participants at the end of stages 1 and 2 of the benchmark.

\subsection{Modeling assumptions}

Participants were of different origins such as companies specialized in civil engineering $(38 \%)$ or in nuclear engineering $(14 \%)$, and education institutions including research centers (48\%). This large pool of participants led to many different numerical approaches and a large number of FE analysis types to describe the structural system were used. According to the feedbacks and lessons drawn from the SMART 2008 benchmark, it appeared that one of the key parameters influencing the structural behavior of the RC specimen was the type spatial discretization used to model the least wide shear wall. Five different FE types (inducing several displacement kinematics at the FE level) were used by the whole pool of participants, namely the 0D type (lumped mass based models), the DM type (discrete element based models), the 1D type (beam element based models), the 2D type (plate and shell element based models) and the 3D type (solid element based models). Examples of meshes used by the participants are shown in Fig. 2.

According to this classification, it was noticed that the most represented type was the $2 \mathrm{D}$ one (63\%), in which most of the models were based on plate and shell elements, used for shear walls and slabs, even if the column would be modelled by beam FEs. It was followed by the 3D type $(28 \%)$, in which the majority of the models were built with solid FEs. OD (3\%), 1D (3\%) and DM (3\%) models were the least represented ones among the whole pool of participants.

SMART 2008 showed the important part played by the shaking table specimen interaction on the results. To help the participants to take the shaking table into account in their modeling strategy and to reduce the scattering related to the different modeling strategies, CEA made a dedicated linear FE model available. The geometry considered in the shaking table model is a simplification of the real geometry. Multilayer shell elements were used with a linear elastic constitutive model. The model was calibrated in such a way that the mass and the stiffness are consistent with the real ones. This was checked by CEA by ensuring the first ten eigenmodes computed by the shaking table model are in agreement with the experimental ones. The FE mesh of the shaking table model provided by CEA is shown in Fig. 3. The interface between the shaking table model upper plate and the SMART 2013 RC model is assumed to be perfect. This trend has been followed by all the participants.

More than $52 \%$ of the participants used it as provided whereas some participants have modified it. The modifications lied in changes in the mesh to reduce the total number of degrees of freedom (DOF). Each participant provided the mass of the different components of the structural system, that is to say the RC specimen, the additional mass and the mass of the shaking table. A statistical description of the results is given in Table 1. The empirical cumulative distribution functions are shown per item in Fig. 4a. The total mass 1 stands for the overall mass of the RC specimen with the additional mass whereas the total mass 2 takes the mass of the shaking table into account. In other words, the difference between total mass 2 and total mass 1 is equal to the mass of the shaking table. One can notice the drop of the total mass 2 in the range 44-68 tons, which may be explained by the fact that some participants did not take the mass of the shaking table into account. The median numerical masses are close to the mean experimental values whatever the indicator considered.

As shown in Fig. 4b, $78 \%$ of the participants used a proportional damping model, considering both the mass and the initial stiffness matrices. $13 \%$ of the participants used a modal damping model whereas only $6 \%$ used a modified Rayleigh damping model with mass and tangent stiffness matrices. The proportional Rayleigh damping model was the most used due to the fact it is easy to implement in a structural model and does not lead to numerical instabilities. Nevertheless, let us

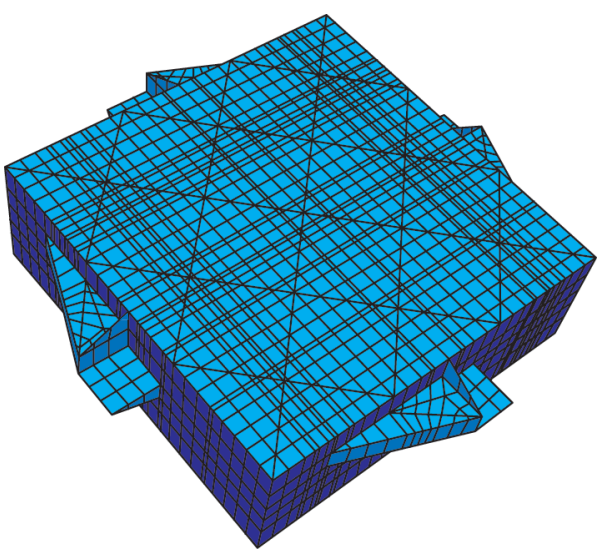

Fig. 3. Mesh of the shaking table model provided by CEA. 
Table 1

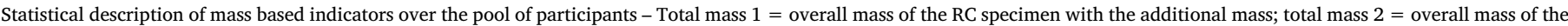
RC specimen with the additional mass and with the mass of the shaking table.

\begin{tabular}{|c|c|c|c|c|c|}
\hline Mass (ton) & RC specimen & Additional mass & Shaking table & Total mass 1 & Total mass 2 \\
\hline Experimental values & 11.890 & 33.940 & 25.000 & 45.830 & 70.830 \\
\hline Mean & 11.390 & 33.942 & 28.242 & 45.332 & 73.574 \\
\hline Standard deviation & 1.662 & 1.425 & 12.694 & 3.087 & 15.781 \\
\hline Coefficient of variation (\%) & 15 & 4 & 45 & 3 & 25 \\
\hline Minimum value & 5.569 & 29.880 & 23.593 & 41.201 & 43.017 \\
\hline Maximum value & 12.977 & 37.791 & 71.176 & 47.018 & 116.854 \\
\hline
\end{tabular}

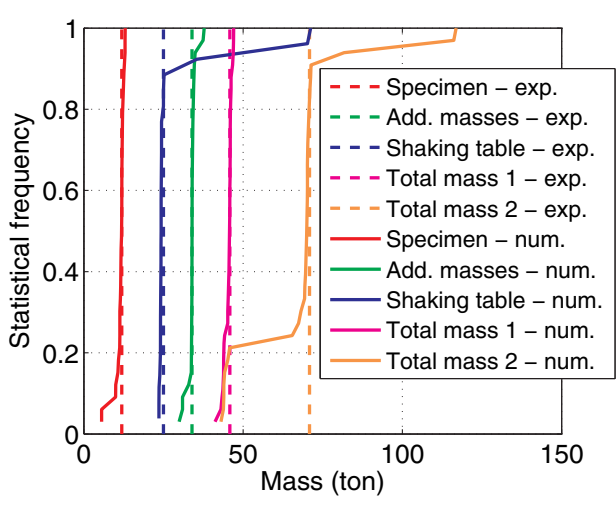

(a) Empirical distribution of some mass based indicators

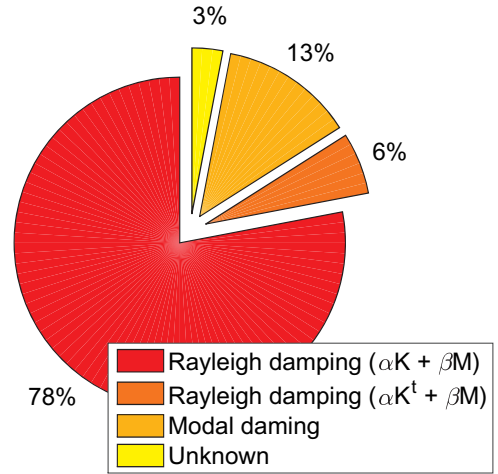

(b) Distribution of some damping models.

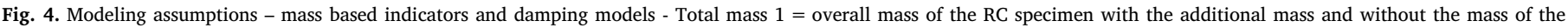
shaking table; total mass 2 = overall mass of the RC specimen with the additional mass and with the mass of the shaking table.

note that viscous forces appear in both low and high frequency ranges, which may lead to the underestimation of the displacement of the system.

\subsection{Constitutive laws}

In order to describe the key characteristics of the nonlinear constitutive laws implemented in the numerical models used by the participating teams, about 50 items were suggested. Around 40 participants answered the description of concrete modeling. The answers were classified according to the participants' origins to point out a possible correlation between the modeling trends and the assumptions. The answers from the participants are shown in Fig. 5a. From the information provided by the participants, it can be assessed that the key mechanisms considered in the concrete constitutive laws used were stiffness degradation intension ${ }^{1}$ and compression softening, and the crack closure effect (also known as unilateral effect). Some mechanisms such as the presence of permanent strains, the concrete heterogeneity or the loading rate effect do not seem to be crucial elements to account for in the constitutive laws' formulation. One can observe differences in the different formulations of the constitutive laws used by the participants, particularly regarding the stiffness degradation description that drives the concrete mechanical behavior during high intensity loadings. This stiffness degradation effect was not taken into account by all the participants meaning that some of them chose to keep a linear elastic approach. Finally, it is noticeable to point out that the complexity of the constitutive models used to describe nonlinear mechanisms does not depend on the participants' origin, since a similar trend was observed on the taking into account of the various mechanisms. Nine items were suggested to describe the steel mechanical behavior. The results are

${ }^{1}$ The fact that the stiffness is decreased in tension means that softening in tension is described by means of damage. shown in Fig. 5b. The key mechanisms included in the steel constitutive law were the yielding, the isotropic hardening, the kinematic hardening and the cyclic and reverse loading related effects. From these answers, it appears that the Bauschinger effect is taken into account; nevertheless, this nonlinear feature is not overriding, due to the level of seismic excitations and the spatial scale of analysis considered here. Likewise, no specific trend regarding the participants' origins can be highlighted. Contrary to the case of concrete constitutive law, the local results related to the steel mechanical behavior were more homogenous. This observation was expected since the steel local behavior is nowadays well mastered and can be described naturally by the constitutive laws available in the commercial computational software. In addition, these results emphasize the fact that the modeling practice related to steel is nowadays shared in the international community whatever the type of institutions considered. Among the whole pool of participants, none of them considered a steel/concrete interface constitutive law to manage the bond degradation.

In order to characterize the local responses of the constitutive laws used by the participants and to facilitate the forthcoming comparisons of results at the structural scale by the participants on the mock-up, a set of local ${ }^{2}$ tests were required. These tests aimed at characterizing both the monotonic and the cyclic response of RVEs made of plain concrete, steel and RC. In other words, specific loading paths are considered to characterize the response of constitutive models at the integration point level. More than $70 \%$ of the participants performed these local tests. In the following, three results from 3 tests over the 10 required are presented and discussed. The first test aimed at assessing the uniaxial stress/strain response of the concrete constitutive laws under cyclic loading before and after reaching the tensile or the compressive strengths. The loading path is shown in Fig. $6 \mathrm{a}$ and the results

\footnotetext{
${ }^{2}$ The adjective « local » refers to the fact that the test had to be carried out at the level of the integration point.
} 


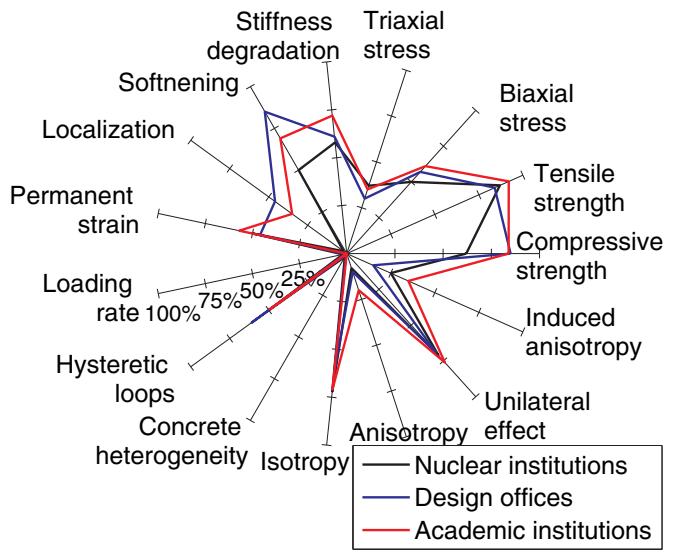

(a) Concrete

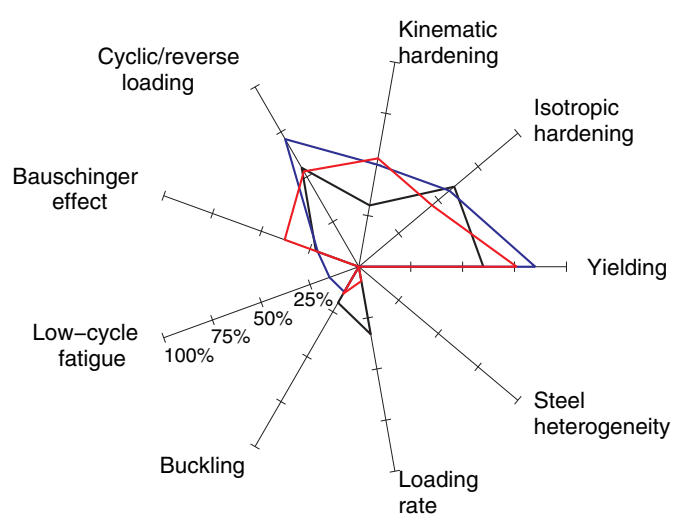

(b) Reinforcing steel

Fig. 5. Key mechanisms used by participants in connection with their origin to describe the material behaviors - percentage with respect to the total number of participants.

in Fig. 6b. A few participants did not take into account nonlinearities related to cracking and therefore, chose to represent concrete as a linear elastic material, as seen in Fig. 6b. However, most of the participants naturally used nonlinear constitutive laws to describe the stiffness degradation and the dissipation in tension due to concrete cracking instead of equivalent linear approaches, as often used in common engineering practices. Despite the fact that the scatter is large for both tension and compression softening paths, these results confirm the key features of the constitutive models previously identified as preponderant.

The second test aimed at assessing the uniaxial stress/strain behavior of the steel constitutive law by means of a tension/compression test. The loading path is shown in Fig. $6 \mathrm{c}$ and the results in Fig. 6d. Some participants did not fulfill the prescribed conditions (prescribed strain path and yield stress). However, this test allows noticing that the steel behavior was modeled mainly by the two well-known constitutive laws, that is to say the Von Mises' law with linear kinematic hardening and the Menegotto Pinto's law [23]. In case of the Menegotto Pinto's law, it is necessary to remember the high number of material parameters that need to be identified to make this law meaningful. Therefore, such a modeling choice was not expected, since the use of constitutive laws with high number of parameters is not conventional in the engineering assessment practices. A Von Mises' law with linear kinematic hardening is commonly used because for moderate seismic levels, low elastic-plastic incursions are expected.

The last test presented in this paper aimed at studying the uniaxial response of a RC RVE, with a reinforcement ratio about $2 \%$, subjected to a cyclic loading (successively membrane, shear and bending), resulting from both concrete and steel behaviors. Only two participants used an integrated RC nonlinear constitutive law based on homogenization principles, [24]. This observation may lead to think this modeling practice is not common whereas it may help to save computational time. The loading path and the results are shown in Fig. 6e and $f$ respectively. It can be noticed that the maximum prescribed displacement leads to exceed the concrete elastic strain limit in tension. Therefore, the remaining mechanical behavior is mainly driven by the steel behavior and the tension-stiffening effect occurring after concrete cracking and steel-concrete stress-transfer. In addition, some models can describe the unilateral effect and allow recovering in quasi-fully way the elastic stiffness when switching from tension to compression. The test ends when it reaches a strain equal to zero. As the steel has previously exceeded its yield stress, plastic strains can be observed. Therefore, a residual tensile stress state is necessary to reach a strain equal to zero. Despite the fact the scatter was important, and consequently the evaluation of dissipation, it is interesting to point out most of the participants considered a quite sophisticated nonlinear description of the RC RVE allowing dealing with both linear and nonlinear ranges. This observation is in agreement with the trend noticed in the case of the first local test and brings us to assess that the confidence in nonlinear models has increased. The equivalent linear approaches that have been used so far within the engineering community seem to be progressively replaced by nonlinear ones.

\subsection{Initial structural calibration}

An important step to assess the predictive capabilities of the nonlinear modelling approaches used by the participants lied in checking the satisfactory calibration of the structural FE models in the linear range. To reach this objective, a two-step calibration process was proposed (i) the calibration of the first three eigenfrequencies and (ii) the dynamic simulation of low intensity time history loadings with a PGA around $0.1 \mathrm{~g}$.

\subsubsection{Initial modal properties}

Modal analyses were asked to the participants. The participants were provided by three sets of boundary conditions by the organizing committee. Only the results obtained with the boundary conditions which are the closest to the experimental ones are presented in this section. The first three eigenfrequencies were asked considering that the RC specimen is connected to the shaking table and is loaded with additional masses. The anchorage points between the actuators and the shaking table are clamped. The participants' results and the experimental values are shown and compared in Table 2. The empirical cumulative distribution functions of the eigenfrequencies are given in Fig. 7. For the first mode (overall bending), the eigenfrequencies identified by the participants were mainly similar. However, for the second and the third modes, the scatter is more important than for the previous one. In case of the third mode, this matter seems to be mainly governed by the choice of the finite elements used (solid, shell, beam elements...). The third eigenmodes of the SMART 2013 specimen allows observing torsion. Therefore, when the specimen is excited with a dynamic loading having a frequency content around the third eigenfrequency and below, shear strain and stresses will appear. To capture this feature, it is more natural to use 2D or 3D models Even though some specific 1D models may take this effect into account. We note also a discrepancy between experimental values, obtained by operational modal analysis technique, and simulation ones, which is increasing for higher order modes. We can refer this observation to the fact that torsional effects could mobilize shear compliance at the foundation of the mock-up, which is difficult to be idealized by FE models. 


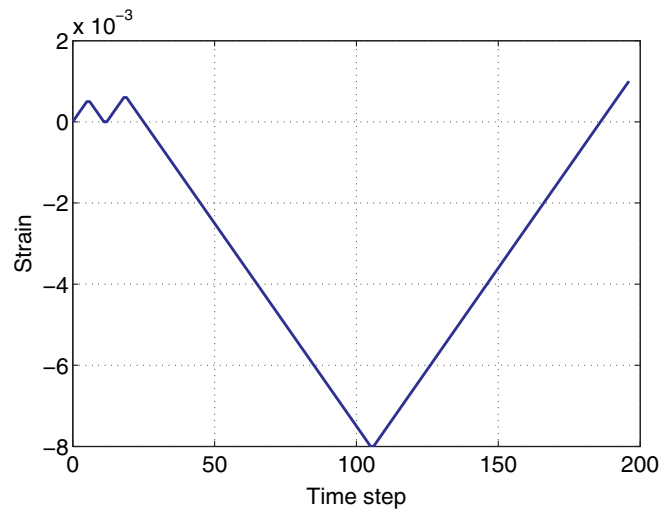

(a) Loading path - concrete.

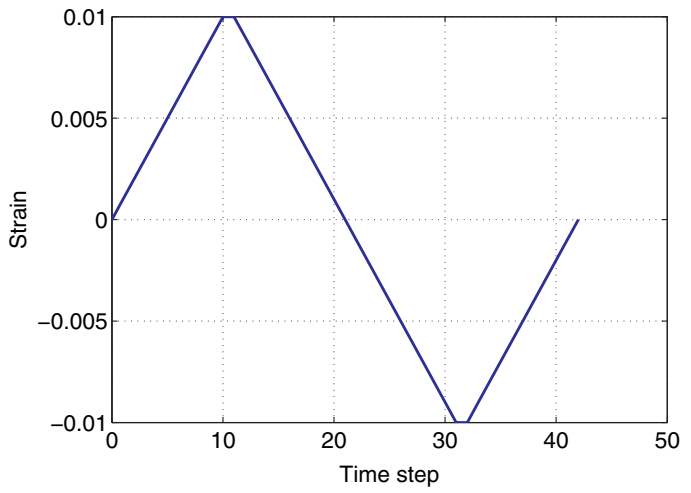

(c) Loading path - steel.

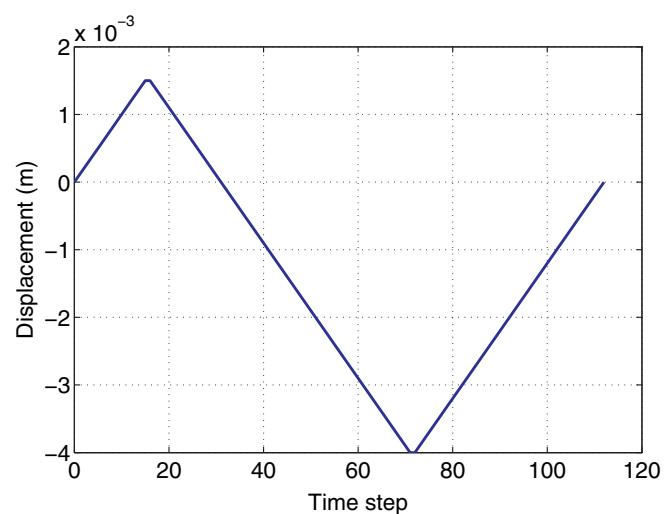

(e) Loading path $-\mathrm{RC}$.

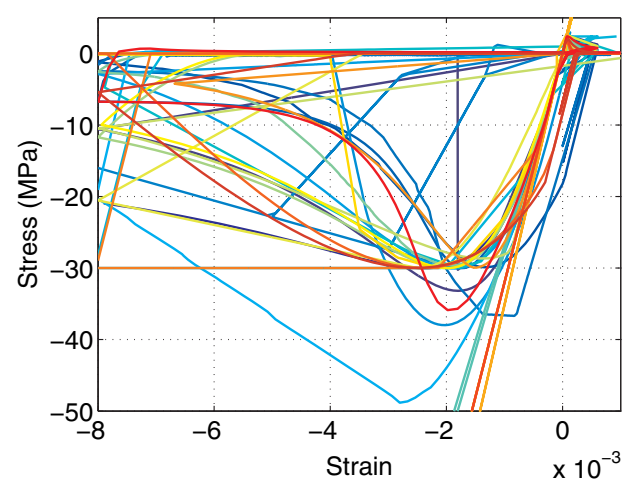

(b) Cyclic response - concrete.

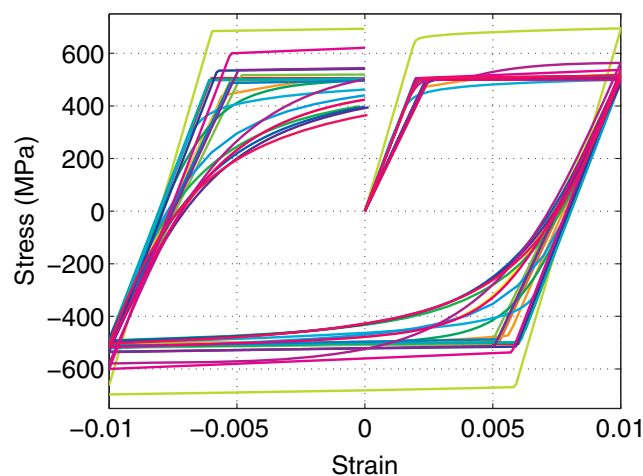

(d) Cyclic response - steel.

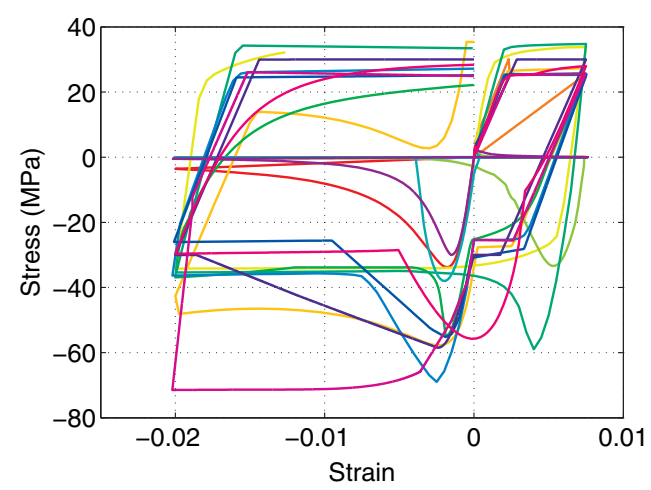

(f) Cyclic response $-\mathrm{RC}$.

Fig. 6. Local cyclic uniaxial responses of RVEs by participants.

Table 2

Experimental/numerical comparison of the first three eigenfrequencies.

\begin{tabular}{llll}
\hline Eigenfrequency $(\mathrm{Hz})$ & First & Second & Third \\
\hline Experimental & 6.28 & 7.86 & 16.50 \\
Mean & 6.69 & 9.93 & 20.55 \\
Standard deviation & 1.36 & 1.77 & 3.54 \\
Coefficient of variation (\%) & 20 & 18 & 17 \\
Minimum & 4.84 & 8.12 & 14.75 \\
Maximum & 12.26 & 14.37 & 29.12 \\
\hline
\end{tabular}

\subsubsection{Dynamic responses for low input ground motions}

This section is devoted to the presentation and the analysis of the results from the transient analyses based on low-intensity input ground motions, where two bi-axial seismic runs were considered (run\#6 and \#7). The first one was a random noise and the second one was the design synthetic input signal scaled at $50 \%$. In this section, the

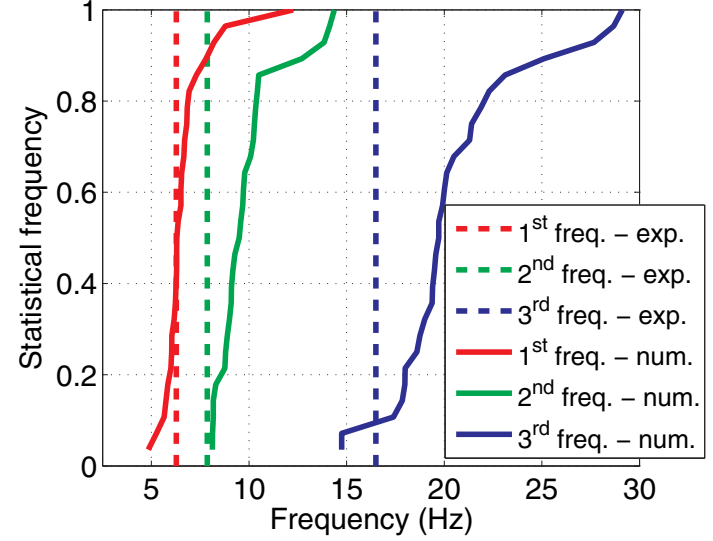

Fig. 7. Empirical cumulative distribution functions of the first three eigenfrequencies. 


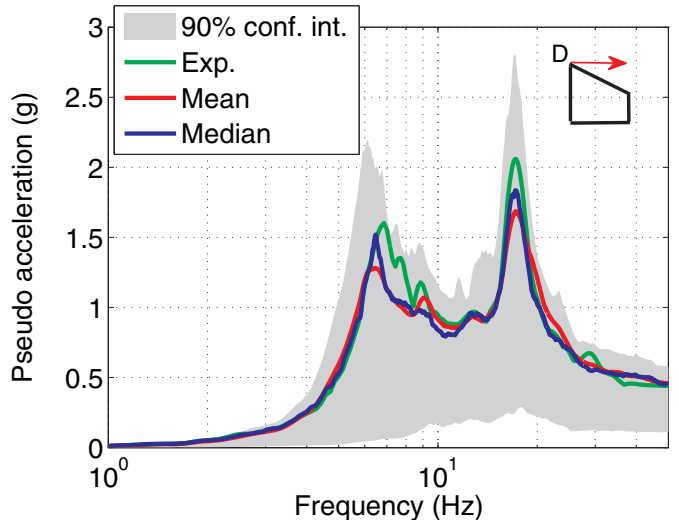

(a) $\mathrm{X}$ direction

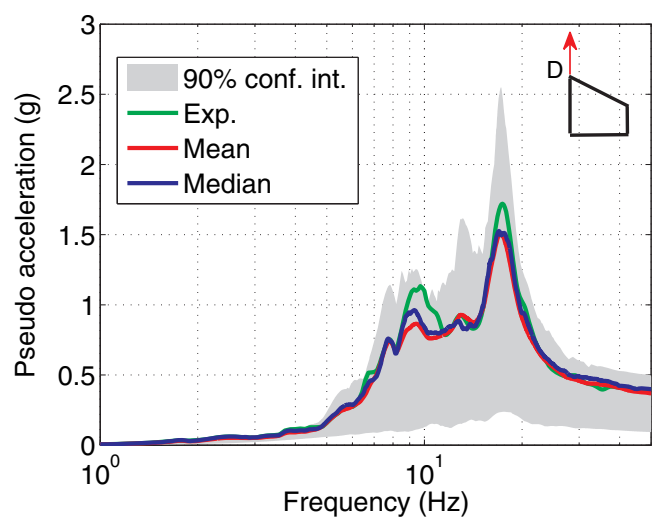

(b) $\mathrm{Y}$ direction

Fig. 8. Experimental/numerical comparison of the FRS - third floor - point D - run \#7.

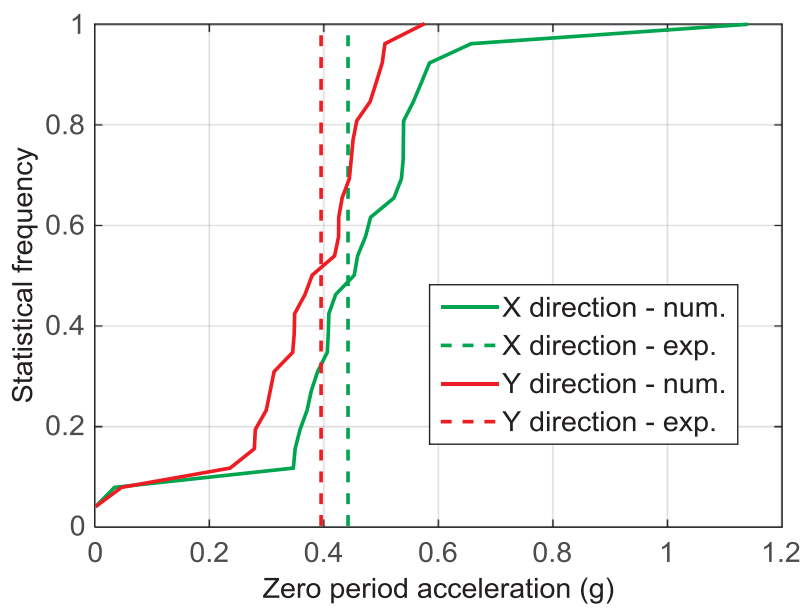

Fig. 9. Empirical cumulative distribution function of the ZPA - third floor - point D - run \#7, computed on the participants' pool.

emphasis is made on the results related to run\#7 only but the trends observed are also in accordance with the ones related to run\#6. The participants were provided with experimental acceleration and displacement time histories (both inputs and outputs) to allow an accurate calibration of the dynamic system in the quasi-elastic range. To analyze the time evolutions of quantities of interest, the point located at the top floor and that exhibits the largest displacement amplitude is considered. It is denoted D. The FRS, the statistical distribution of the zeroperiod acceleration (ZPA) and the inter-story displacement (ISD) are analyzed. Despite the fact only the results obtained in case of run\#7 are presented, it is important to mention that similar trends have been observed for other measurement points. The ZPAs were computed from the FRS considering a frequency equal to $1000 \mathrm{~Hz}$. Fig. 8 shows the statistical results of the FRS computed for $5 \%$ damping in case of run\#7. The results clearly show that the numerical models could capture the main peak frequencies around $6 \mathrm{~Hz}$ and $16 \mathrm{~Hz}$ (first and third modes) in $\mathrm{X}$ direction and $8 \mathrm{~Hz}$ and $16 \mathrm{~Hz}$ (second and third modes) in $\mathrm{Y}$ direction. In addition, when looking at the results in the high frequency range, the ZPA appears as being well captured. The scatter is less important in the high frequency range than in the low frequency range. The statistical distribution of the ZPAs shown in Fig. 9 confirms this observation. This means that the numerical models were calibrated in a satisfactory way; they can describe the high frequency responses of the dynamic system. However, as it can be noticed, the data are highly scattered. Several reasons can be invoked to explain this scattering: the FE type, the time step, the way to apply the loading or the way to model the shaking table. Further investigations are still needed to identify the most preponderant contributing factor.

The empirical cumulative distribution function related to the maximum values of the ISD is shown in Fig. 10. The experimental values show that the ISD has increased - as expected - from the bottom (ISD between the ground floor and the first level; denoted $\mathrm{ISD}_{00-10}$ ) to the third level (ISD between the second level and the third level; denoted $\mathrm{ISD}_{20-30}$ ) in both $\mathrm{X}$ and $\mathrm{Y}$ directions. The numerical models were not able to capture this effect, which remains quite local. Nevertheless, it is worth noticing that the ISD values are very low (lower than $2 \mathrm{~mm}$ ). Therefore, the comparison between the numerical results and the numerical outputs should be made with care. Especially, the experimental curves should be represented with their standard deviations.

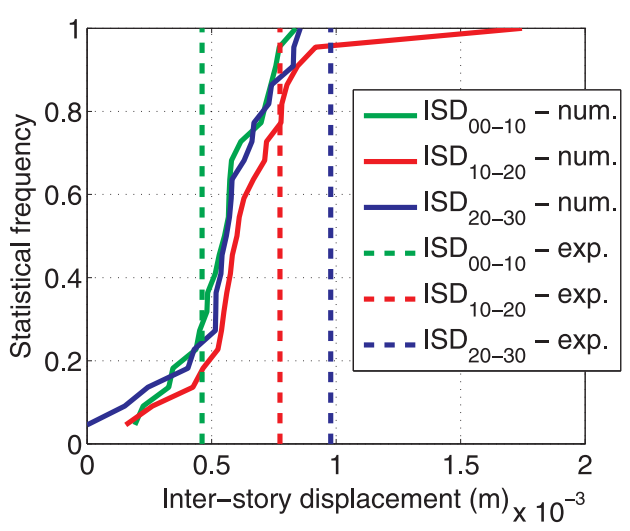

(a) $\mathrm{X}$ direction

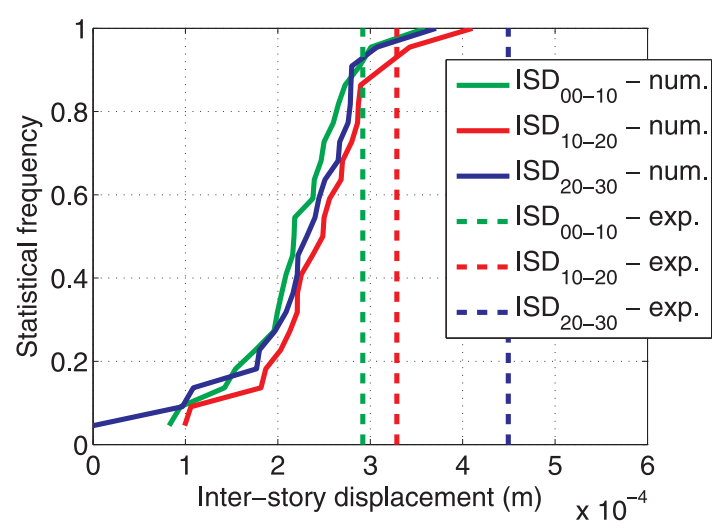

(b) Y direction

Fig. 10. Empirical cumulative distribution functions of the maximum absolute values of the ISD - point D - run \#7, computed on the participants' pool. 
Table 3

Damage thresholds for each structural indicator $-\mathrm{h}=$ inter-story height $(1.20 \mathrm{~m})$.

\begin{tabular}{|c|c|c|c|}
\hline \multirow[b]{2}{*}{ Indicators ( $\mathrm{X}$ and $\mathrm{Y}$ directions) } & \multicolumn{3}{|l|}{ Damage thresholds } \\
\hline & Light damage & Controlled damage & Extended damage \\
\hline Inter-story drift $\left(\mathrm{ISD}_{20-30}\right)$ & ISD higher than $3 \mathrm{~mm}\left(\mathrm{~h}^{(*)} / 400\right)$ & ISD higher than $6 \mathrm{~mm}\left(\mathrm{~h}^{(*)} / 200\right)$ & ISD higher than $12 \mathrm{~mm}\left(\mathrm{~h}^{(*)} / 100\right)$ \\
\hline Peak frequency shift (1st peak frequency) & Frequency decay of $15 \%$ & Frequency decay of $30 \%$ & Frequency decay of $50 \%$ \\
\hline
\end{tabular}

As a partial conclusion, the numerical results exhibit an overall trend close to the experimental results. Considering that the numerical models behave in the linear domain, it can be concluded they are well calibrated. The modal analyses have highlighted an accurate prediction of the first eigenfrequency and an overestimation of the second and third ones, compared with the ones identified experimentally. The FRS, all computed by the same methodology available in Cast3M from the participants' results, are in agreement with the experimental measurements. This conclusion has been explicitly drawn in this paper in case of point D. It is worth noticing that a similar trend has been observed in the other observation points studied within the framework of this benchmark. Finally, the results show that the numerical models did not predict quite well the ISD. Indeed, considering the fact the magnitudes of the experimental data are in between $10^{-4} \mathrm{~m}$ and $10^{-3} \mathrm{~m}$, the quality of the prediction can be considered as being reasonable.

\section{Assessment of the seismic safety margins}

In this section, the results from the structural robustness and probabilistic vulnerability analyses are presented. The results provided by the participants were post-processed in order to quantify the seismic safety margins by means of two mechanical indicators that are defined in the following. The analysis was conducted seismic sequence by seismic sequence. The analysis presented in this section allows (i) quantifying the seismic safety margins, (ii) studying the damaging effect of an aftershock and (iii) studying the relevancy of the two indicators used regarding the experimental evidence. The main results presented in this section are related to stage 3 of the benchmark and, come from blind computations made by the participants. Finally, we present an outline of results of the restricted panel of participants in stage 4, dedicated to the vulnerability analysis through fragility curves calculations.

\subsection{Driving ideas}

The specimen was subjected to several transient seismic signals and therefore, was gradually damaged. These transient signals were sorted according to three sequences in order to quantify the damaging power of each seismic sequence (see [20] for a detailed description of the experimental campaign). Each sequence was composed of several scaled transient signals, based on a nominal signal. In a given sequence, the loading factor, defined as the ratio between the PGA of the scaled signal and the PGA of nominal signal and denoted $\lambda_{i}$, was increased up to $100 \%$. In order to assess the safety level of the RC structure, two indicators (or engineering demand parameters) were defined and analyzed: (1) the maximal ISD between the second and the third floors, and (2) the frequency shift related to the first peak identified from the FRS computed at point $\mathrm{D}$. Both $\mathrm{X}$ and $\mathrm{Y}$ directions were analyzed. The first indicator is inspired by the usual criterion devoted to RC multistory moment-resisting frames [25], while the second one seems more adapted to the equipment seismic analysis from floor response spectra. The ISD is a local indicator that can be associated with the ductility capacity of the RC structure and that represents the capability of the numerical models to reproduce the differential displacements between two stories by comparison with experimental measurements. The peak frequency shift (PFS) is a structural indicator that represents the capabilities of the numerical models to capture the overall behavior of the specimen while the stiffness degradation and dissipation are increasing. Three damage thresholds, allowing the definition of three engineering damage states (light, controlled and extended damage) have been introduced for each mechanical indicator. They are presented in Table 3. These damage indicators can correspond to the ISDs' value or to the PFSs exhibited by the structural system. For each participant, the first peak frequency was identified from the first transient signal of each seismic sequence (i.e. run\#7, \#11 - reduced Northridge main shock with targeted PGA $0.20 \mathrm{~g}$ - and \#21 - aftershock with targeted PGA $0.14 \mathrm{~g}$, see [20]), allowing the definition of the "reference peak frequency". This reference peak frequency is compared with the first peak frequency of the following transient signals in a given seismic sequence to estimate the PFS. The experimental values of these two mechanical indicators are compared with the numerical ones considering the damage thresholds to estimate the seismic safety margins, both in terms of robustness of the structure and of impact on spectral amplification transferred to equipment, caused by the frequency shift.

Regarding the ISD, the threshold have been selected according to the FEMA 273 standard [26]. According to this standard, three limit states should be considered: collapse prevention (CP), life safety (LS), immediate occupancy (IO). For each limit state, specific thresholds are introduced. More precisely, the values given by the FEMA 273 are $2 \%$, $1 \%$ and $0.5 \%$ for the CP, LS and IO limit states respectively. Because SMART project is related to nuclear buildings, a safety factor equal to 2 has been introduced. Therefore, the values of the thresholds considered in the SMART project are $1 \%, 0.5 \%$ and $0.25 \%$ (see Table 3.). Regarding the PFS, the literature review clearly shows that this quantity was not studied in depth. PFS thresholds can be justified not only regarding the FRS frequency content demand for equipment seismic assessment but also by some engineering practice of reducing the Young's modulus by $50 \%$ in cracked zones of bended RC sections in linear elastic calculations, i.e. a frequency decay of about $30 \%$. Given this value, $15 \%$ and $50 \%$ have been introduced to allow quantifying lower and higher damage states. The Authors agree with the fact the chosen values can be discussed. However, this index seems to be useful to quantify the impact on spectral amplification transferred from the ground to the equipment, caused by the frequency shift.

\subsection{Inter-story displacements based indicator}

In this section, the structural response of the RC specimen is quantified by means of a displacement based indicator, which is the ISD. The experimental measurements are compared with the results provided by the benchmark's participants; they are plotted in Fig. 11 for all loadings of each seismic sequence. First, the case of the design level sequence is presented in both $\mathrm{X}$ and $\mathrm{Y}$ directions in Fig. 11a and $\mathrm{b}$ respectively. The confidence interval is thin around the median, showing a low scatter of the numerical values. The experimental values never exceed the light damage threshold during the whole seismic sequence. The median numerical results are in satisfactory agreement with the experimental measurements. These results show that the numerical models can predict the maximum experimental ISD. Nevertheless, one can notice that the experimental results are slightly underestimated in the $\mathrm{Y}$ direction but it is difficult to point out any trend due to the fact that the experimental values are very low, making the experimental 


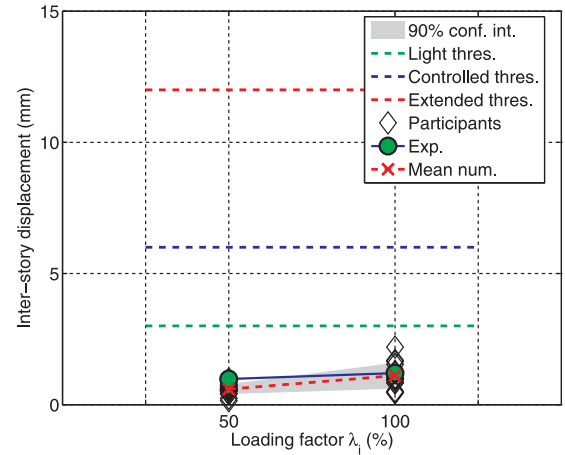

(a) $\mathrm{X}$ direction - Design level - run \#9 (Realized PGA $=0.22 \mathrm{~g}$ )

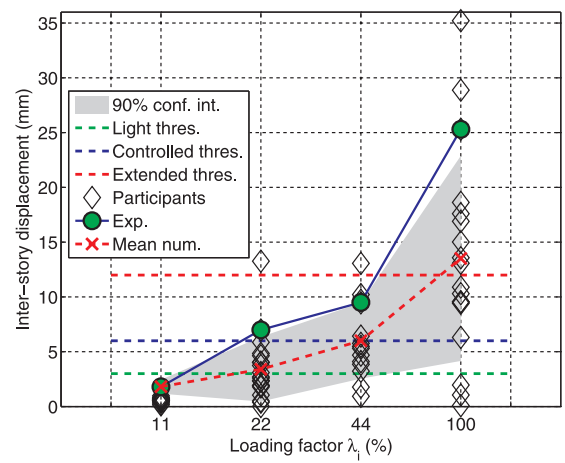

(c) $\mathrm{X}$ direction - Northridge main shock - run $\# 19$ (Realized PGA = $1.1 \mathrm{~g}$ )

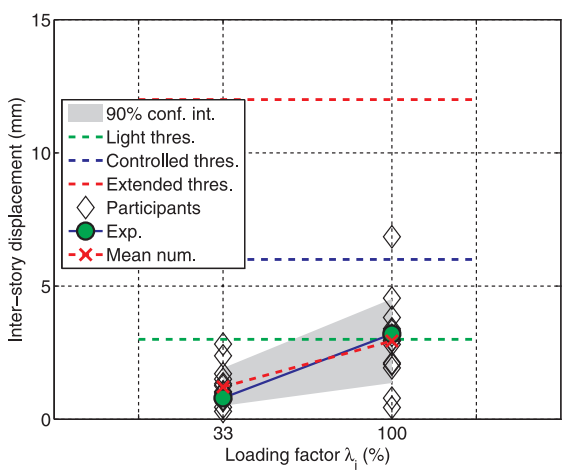

(e) X direction - Northridge aftershock - run \#23 (Realized PGA $=0.70 \mathrm{~g}$ )

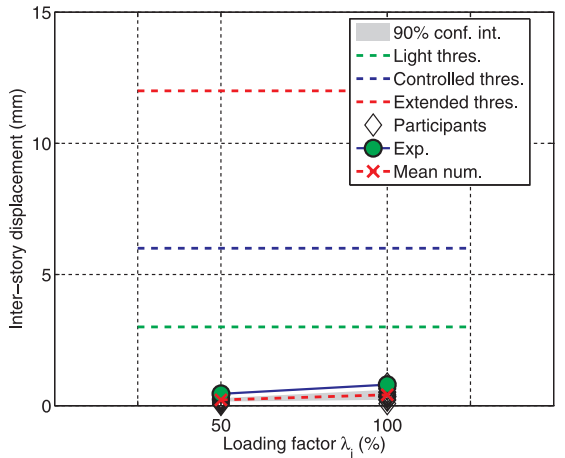

(b) Y direction - Design level - run \#9

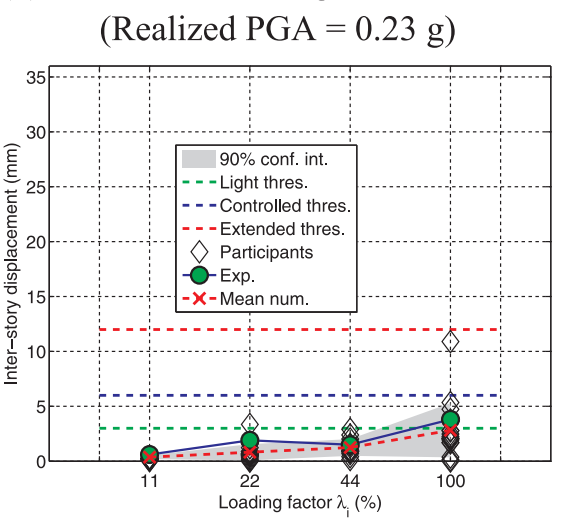

(d) Y direction - Northridge main shock - run \#19 (Realized PGA $=0.94 \mathrm{~g}$ )

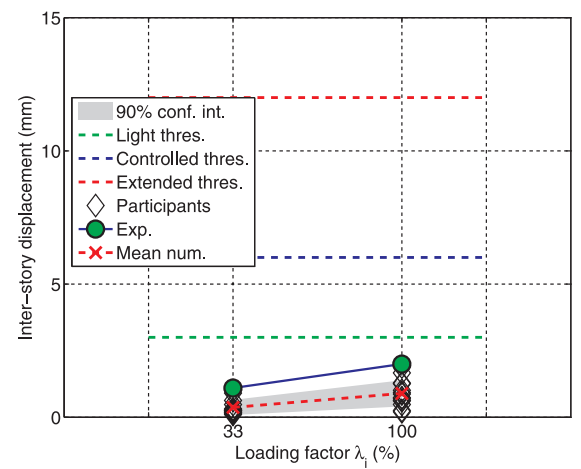

(f) Y direction - Northridge aftershock - run \#23 (Realized PGA $=0.40 \mathrm{~g}$ )

Fig. 11. Seismic safety margins based on a displacement based indicator - experimental/numerical comparisons, computed on the participants' pool.

uncertainties important. Therefore, it can be assessed that the description of shear between two consecutive stories seems to be satisfactory when considering the design level. Second, the results obtained in case of the Northridge main shock sequence are presented in Fig. 11c and $\mathrm{d}$ for both horizontal directions respectively. The RC specimen was highly damaged during this seismic sequence. In the $\mathrm{X}$ direction, a gap is observed between the experimental values and the median numerical results. The numerical models led to an underestimation of the ISD. For the second transient signal that corresponds to a loading factor equal to $22 \%$ of the main shock, the experimental ISD exceeds the controlled damage threshold, whereas the median numerical results are just above the light damage threshold. It is worth mentioning that even though the experimental values are underestimated, the numerical models predicted the general trend of the ISD variations with respect to the loading factor quite satisfactorily. In the $\mathrm{Y}$ direction, the results clearly show that the numerical models are relevant enough to assess the experimental behavior of the structure. The mean results demonstrate that the numerical approaches used are quite accurate when the structure is strongly excited and therefore, when the experimental displacement measurements are high. This observation is in agreement with the ones made within the framework of CAMUS research program [6,7]. Last, the case of the Northridge aftershock sequence is analyzed; the results are presented in Fig. 11e and $\mathrm{f}$ for both $\mathrm{X}$ and $\mathrm{Y}$ directions respectively. The experimental ISDs are close to the light damage threshold in the $\mathrm{X}$ direction and below it in the $\mathrm{Y}$ direction. The median numerical results are in agreement with the experimental measurements in the $\mathrm{X}$ direction whereas they underestimate them in the $\mathrm{Y}$ direction. It is also interesting to point out that in case of the $\mathrm{X}$ direction, the results led to conclude that the RC structure was only lightly damaged during the Northridge aftershock sequence and this assessment is in accordance with the experimental observations made [20]. 


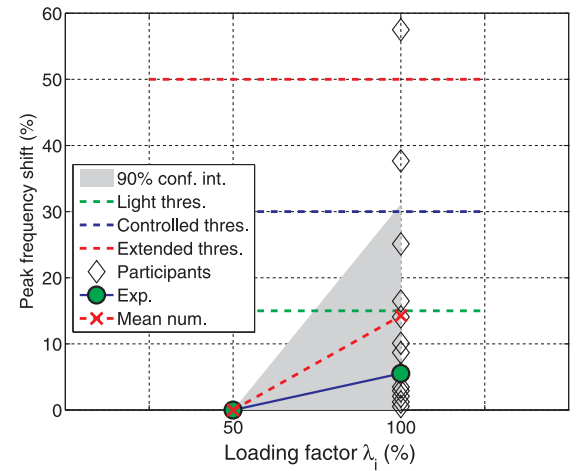

(a) X direction - Design level - run \#9 (Realized PGA $=0.22 \mathrm{~g}$ )

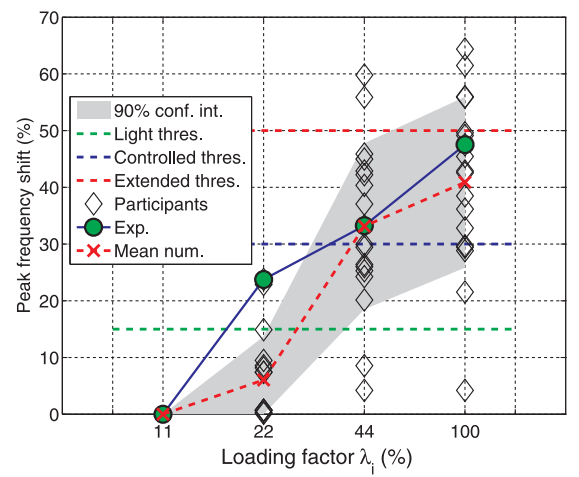

(c) $\mathrm{X}$ direction - Northridge main shock - run \#19 (Realized PGA $=1.1 \mathrm{~g}$ )

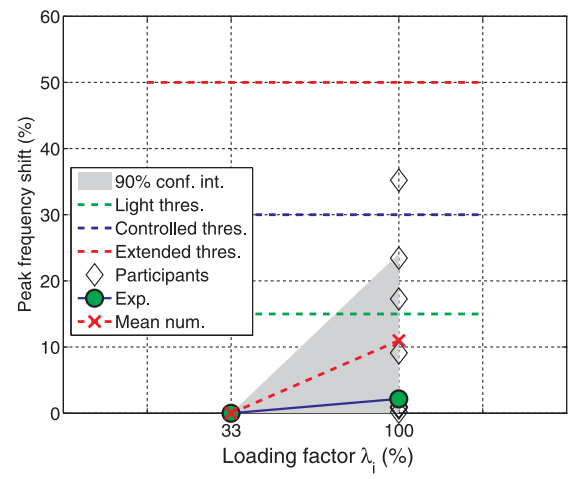

(e) $\mathrm{X}$ direction - Northridge aftershock - run \#23 (Realized PGA $=0.70 \mathrm{~g}$ )

Fig. 12. Seismic safety margins based on a peak frequency based indicator - experimental/numerical comparisons, computed on the participants' pool.

\subsection{Peak frequency shift based indicator}

The structural response is now quantified by another indicator, namely the PFS. This indicator naturally takes into account the stiffness degradation due to damage at the structural member scale. In other words, PFS allows defining a damage measure that accounts for the stiffness degradation which occurs in the whole structure during the seismic loadings. The numerical results coming from the pool of participants are compared with those coming from the experimental measurements in Fig. 12 for each seismic sequence, in case of both horizontal directions. First, the results obtained in case of the design level are shown in Fig. 12a and b for both $\mathrm{X}$ and $\mathrm{Y}$ directions respectively. In the $\mathrm{X}$ direction, experimental values and numerical median are below the light damage threshold. The numerical results exhibit a large scatter, as shown by the $90 \%$ confidence interval. In the $\mathrm{Y}$ direction, the median of the numerical values is close to the experimental results. The numerical models are able to capture the same peak

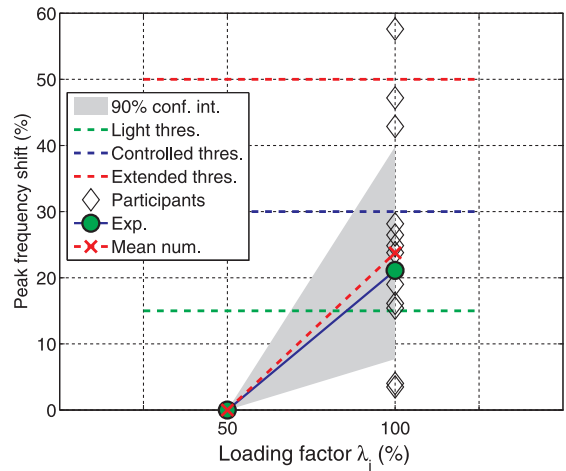

(b) Y direction - Design level - run \#9 (Realized PGA $=0.23 \mathrm{~g}$ )

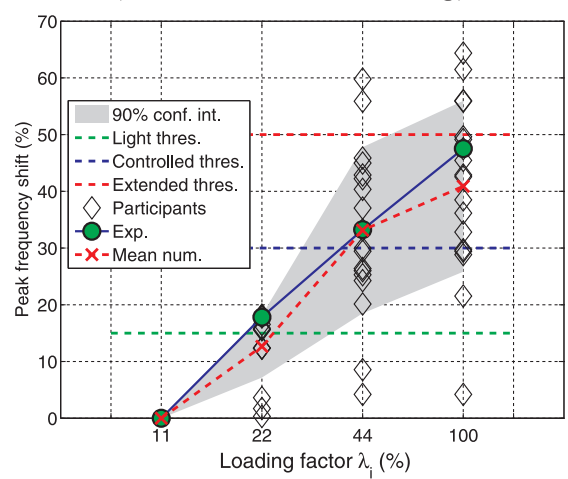

(d) Y direction - Northridge main shock - run \#19 (Realized PGA $=0.94 \mathrm{~g}$ )

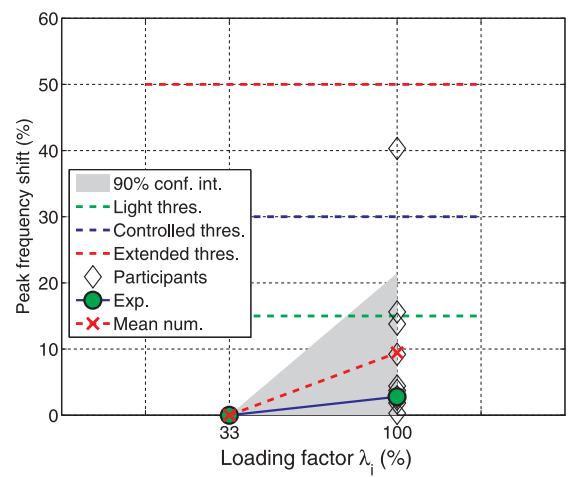

(f) Y direction - Northridge aftershock - run \#23 (Realized PGA $=0.40 \mathrm{~g}$ ) frequency shift that goes beyond the light damage threshold (mean shift around $21 \%$ ) but remains below the controlled damage (shift equal to $30 \%)$. In case of the $\mathrm{Y}$ direction, the mean PFS captures the experimental peak frequency shift well in case of the design level. In case of the $\mathrm{X}$ direction, the participants underestimated the experimental value. However, both results show that the structural system does not behave linearly when considering the seismic level for which it has been designed, the nonlinearity level being light. In other words, it is justified to use nonlinear assessment methods even when dealing with design levels. On the contrary, the use of linear constitutive models would lead to an overestimation of the internal forces and therefore, to a too conservative design. Second, Fig. 12c and d shows the experimental/numerical comparisons of the PFS evolution during the Northridge main shock sequence in both $\mathrm{X}$ and $\mathrm{Y}$ directions respectively. Most of the participants took the cumulative damage into account because of the seismic loading history. In both directions, the medians of the numerical values are in satisfactory agreement with the experimental peak 
frequency shifts for the different transient signals. Except for run \#13 ( $22 \%$ of the main shock), the numerical estimation of the structural damage is in line with the experimental one. Despite the fact that the highest PGA of the most intense component of the Northridge main shock is almost equal to $1.8 \mathrm{~g}$ (7 times higher than the PGA related to the design signal), one can observe that the extended damage threshold is not exceeded. This is true not only in case of the experimental values but also in case of the median numerical results. In this case, the numerical models succeeded in assessing the nonlinear behavior of the structure under a blind benchmark condition in a satisfactory way. Last, Fig. 12e and $\mathrm{f}$ shows the results related to the Northridge aftershock sequence in both horizontal directions respectively. The medians of the numerical results overestimate the experimental peak frequency shift but the light damage threshold is never exceeded whatever the direction considered. This indicator highlights the fact that the aftershock signal does not lead to additional damage of the RC specimen. In addition, the nonlinear assessment approaches used by the participants appear as being conservative.

\subsection{Vulnerability analysis and fragility curves calculations}

Stage 4 of the benchmark was dedicated to fragility curves calculations, from time-history analyses. Participants were invited to implement their calculations with the structural model developed for the previous stages and validated on experimental results. In order to get a more realistic exercise, the shaking table FE model was replaced by simplified equivalent foundation impedances - having been fitted to the reduced scale - at the base of FE models of the mock-up. The first step aimed at comparing methods for evaluating fragility curves with the linear structural model, using the participants' practice. Two methods were allowed: the regression method and the maximum likelihood principle method. The participants only used the regression method. In practice it has not been observed that results obtained by this second method were more relevant than by the linear regression in this benchmark; nevertheless we can perform both in order to choose the conservative envelope. In addition, the Latin hypercube sampling approach based on a set of time-history analyses was used. Equivalent lognormal distribution parameters of fragility curves are fitted from their results. Then the second step focused on fragility curves calculation in the nonlinear range by means of the regression method. Both steps allows to determine the median capacity $A_{m}$ and the log-standard deviation $\beta$, depicting the aleatory and epistemic uncertainties, see for instance [27]. So the fragility curves can be expressed from the probability of failure conditioned on the seismic intensity measure $a$ larger than the structural capacity $A$ by means of the reduced centered random Gaussian cumulative distribution function $\Phi$, defined by the median capacity $A_{m}$ and standard deviation $\beta$ :

$P_{f}(a)=\Phi\left(\frac{\ln \left(\frac{a}{A_{m}}\right)}{\beta}\right)$

The structural properties which were considered as random variables are the following ones; in the first part of stage 4: the foundation stiffness and damping coefficients and in the second part of stage 4: tensile concrete strength, structural damping ratio. Lognormal probabilistic distributions are assumed for all these random variables. The same two damage indicators were considered: the ISD at point D in the $\mathrm{X}$ direction and the PFS, with the same three levels as those presented in the previous sections. Three seismic intensity measures were proposed: the PGA, the cumulative absolute velocity (CAV), the structure-specific average spectral acceleration (ASA), which is the area obtained by integrating the ground motion response spectrum between half and one times the first eigenfrequency of the structure, see [28]. A database of 100 pairs of scaled synthetic non-stationary accelerograms (X and Y directions), compatible with median and $\pm \sigma$ spectra, for a specific relevant seismic event $(\mathrm{Mw}=6.5, \mathrm{D}=9 \mathrm{~km})$, was generated by Code_Aster and provided to participants. It was expected this database to be sufficient to cover the whole range of damage indicators to be analyzed in fragility curves computation. A reduced pool of 7 participants answered to stage 4. Significant computational resources were needed for these calculations, but easily helped by parallel computing. From the comparison of the log-standard deviations obtained on the computed fragility curves, in case of both ISD and PFS damage indicators, it appears that the discrepancy is higher using the CAV intensity measure. It seems that this measure is the less relevant for such RC structure, leading to the highest log-standard deviation. This observation may be linked with the fact its definition is more fitted to cumulative dissipation processes, such as yielding. The frequency dependent ASA indicator led to the results with the lowest log-standard deviations. This may be explained by the fact it is more fitted to structures whose evolving eigenfrequencies are associated with material damage processes. The variability of the seismic motions was observed to produce the most noticeable effect on the results. Furthermore, for the three levels of the two damage indicators, fragility curves computations based on nonlinear simulations give always higher values of the mean capacity and lower values of the probability of failure than those obtained using linear structural calculations. This confirms the ability of nonlinear structural transient analyses to assess the existence of seismic safety margins; and also their ability to be used to avoid some overestimation of the seismic fragility and refine the structural fault characterization needed in probabilistic safety analyses. Finally, it has been observed from the responses provided by the participants that there is a large scatter in the methodology (calculation and practice) to establish the fragility curves for engineering office purposes: methodological guides could be useful to facilitate the practice in design offices.

\section{Main findings and lessons learnt from the international benchmark}

In this section, the main key points highlighted during the benchmark that have been discussed with the benchmark's participants are reported. The main findings reported herein have been shared with the benchmark's participants during the final workshop jointly organized by CEA, EDF and partially endorsed by the IAEA at CEA center located in Saclay (France) in November 2014.

\subsection{Modeling assumptions}

SMART 2013 international benchmark has been the opportunity to draw a panel of engineering practices to assess the beyond design behavior of a complex RC specimen subjected to seismic loadings. The modeling assumptions and feedbacks from all the participating teams were shared during the final international workshop held in November 2014 and several key points appeared as being crucial: (i) the type of constitutive laws to consider in order to describe the mechanical behavior of the constitutive material (in particular concrete), (ii) the choice of the damping model and (iii) the way of applying the seismic loading. First, regarding the modeling assumptions related to the constitutive laws, most of the participants agreed with the importance of accounting for the nonlinear mechanisms responsible for the material dissipation and stiffness degradation in their structural model. A consensus has been reached on the fact that equivalent linear approaches remain inappropriate when dealing with the seismic safety margins assessment of complex buildings, both in terms of RC structural robustness and of floor spectra for equipment analysis, and therefore, with the beyond design behavior. Most of the participants used constitutive laws based on either continuum damage theory (including smeared crack models which are a particular type of damage models [29]) or coupling damage/plasticity theory. It can be noticed that none of the participant used recent techniques allowing the propagation of 
displacement discontinuities in the continuum [30,31]. This can be explained by the fact that these techniques are still mostly used within the scientific community and still need to be transferred to the engineering community. Second, the question of the choice of the damping model remains an important issue and no specific consensus has been reached. However, in case of the use of constitutive laws including hysteretic effects, no specific reduction of the viscous damping contribution was noticed. This observation highlights the fact that the quantification of the material dissipation contributing in the structural damping is an issue that still needs to be studied. In addition, the use of damage-driven damping models remains rare, which confirms the aforementioned need. Last, as one of the main lessons from SMART 2008 project [15], the sensitivity of the numerical results with respect to the way of applying the seismic loading to the structural system has been confirmed. A consensus on the best practice to follow was reached. More specifically, most of the participants agreed with the necessity to include the shaking table in the structural model. It is interesting to notice that this practice was initiated within the CAMUS project $[6,7]$. At this time, the shaking table was roughly modelled by including translational and rotational springs coupled with a rigid plate which was connected to the specimen. The issue lied in finding the appropriate stiffness of the springs to ensure the first eigenfrequencies were calibrated satisfactorily. The fact that most of the participants used a shaking table model goes in the same direction. However, the identification process of the stiffness and mass parameters of the model are now better controlled. In this way, the initial dynamic properties of the system can be well captured and the seismic loading can be input at the actuator level. Most of the participants made the choice to input the actuator displacement time histories, which allowed accounting for the full kinematics of the system. However, this practice requires checking the consistency of the frequency contents of the numerical and the experimental acceleration responses at the shaking table upper plate.

\subsection{Predictive capability of nonlinear seismic assessment methodologies of} the SMART 2013 specimen beyond design behavior

The assessment of the predictive capability of nonlinear structural models when dealing with the beyond design behavior requires to control their initial state, that is to say, to ensure they are well calibrated in the elastic range. This aspect has been addressed in a specific stage of the benchmark and one ended up with the fact that the initial modal properties of the dynamic system were well captured, the acceleration based responses were also satisfactorily described whereas the displacement based quantities were underestimated. However, the maximum value of the displacement being lower than $1 \mathrm{~mm}$, the weight of the experimental uncertainties become important and therefore, no drastic conclusion could be drawn from this observation. It is important to mention that at this stage, no specific damage was expected. Then, it appeared that most of the participants succeeded in calibrating their structural models when dealing with low-level seismic loadings. The quantitative analysis of the mechanical indicators computed from the results provided by the benchmark's participants was then carried out under a blind condition. Among the indicators studied, it appeared that the stiffness degradation, occurring mainly during the Northridge main shock seismic sequence, was satisfactorily captured by most of the participants. In other words, the structural dissipation and material degradation are described in a satisfying manner thanks to the use of nonlinear constitutive laws. Consequently, the PFS appeared as being particularly well captured along the experimental campaign. However, similarly to the case of the low-level seismic loadings, the ISDs were underestimated on average. No specific consensus the key factors explaining this observation over came up during the international workshop; this could be linked to the increasing confidence interval of computed results with the PGA level, as obtained by the participants. However, the nonlinear approaches seem to exhibit different capabilities depending on the nature of the quantity to be described.
Indeed, member scale degradation related quantities (such as PFS) seem to be captured in an easier way than local degradation related ones (such as ISD). Another point of interest is related to the relevancy of the prediction of the SMART 2013 seismic behavior specimen during the Northridge aftershock sequence. The displacement based quantities were badly predicted due to the fact only some constitutive laws accounted for residual strains, which were important to be considered since an important damage increase occurred during the previous seismic sequence. However, satisfactory results were obtained regarding the acceleration based quantities, especially given the fact a pretty good match has been obtained in case of the Northridge Main Shock.

\subsection{Seismic safety margins of the SMART 2013 RC specimen}

As a key objective of the SMART 2013 project, seismic safety margins of the RC specimen have been quantified both experimentally and numerically, by means of the results provided by the participants. To this end, two types of thresholds and three damage levels for each of them were introduced, allowing the definition of three damage states: light, controlled and extended. It is important to mention that the damage levels have been identified from both the published literature in case of wall-based structures and the feedback from the SMART 2008 experimental campaign [17]. Regarding the design level, the ISD led to conclude that no damage appeared (see Fig. 11b) whereas the PFS led to conclude that small damage appeared (see Fig. 12b). The experimental observations were in agreement with the last conclusion, even in case of the design level, small nonlinearities mainly related to concrete cracking appeared and it is crucial to consider nonlinear approaches to capture this effect. Regarding the Northridge main shock, the analysis of the ISD led to conclude that the specimen is highly damaged since the extended damage threshold is overcome by almost a factor 2 whereas the results expressed in terms of PFS revealed that the extended damage threshold is not overcome at all. Again, the experimental observations were in agreement with the conclusions that could be drawn from the PFS. Indeed, besides localized cracks observed on the shear walls and on the slabs, a main crack appeared at the interface between the foundation and the least wide shear wall leading to concrete crushing due to the compressive failure. However, it is worth mentioning that concrete crushing remained confined to a limited area as it can be observed during the experiment, see Fig. 10c of [20]. Therefore, the description of the damage state given by the PFS at the end of the Northridge main shock seems in better agreement with the experimental observations than the one given by the ISD. Regarding the Northridge aftershock sequence, both indicators led to similar conclusions even though the ISD captured a damage increase since the light damage threshold expressed in terms of ISD was exceeded (see Fig. 11e). However, as mentioned previously, the experimental observations confirmed the fact that the Northridge aftershock did not lead to significant damage increase. From the aforementioned discussion, it appears that the choice of the structural indicator to describe the structural damage is a crucial question since the quantification of the safety level is a consequence of it. Within the framework of SMART 2013 project, the PFS indicator appeared as being more appropriate than the ISD, based on experimental observations. In addition, defining the robustness as "the ability of a structure to withstand extreme events without being damaged to an extent disproportionate to the original cause", the SMART 2013 specimen can be qualified as robust since only moderate crack pattern was observed after the Northridge main shock having a PGA higher than 4 or 5 times the design PGA, in accordance with numerical results obtained by participants. This trend was confirmed by the results expressed in terms of PFS. In particular, the aftershock does not lead to significant additional damage in terms of PFS: this conclusion is relevant with respect to the equipment safety analysis.

The last point to be reported concerns the dynamical behavior of the representative specimen of a typical piping with a valve, modelled by a lumped mass, described in [20], set-up at the third floor in the RC 
mock-up, excited by its ends which were clamped on the walls. Three three-directional accelerometers allowed to monitor the dynamic transient responses of the valve. Despite the restrictions stated in [20], and the fact that no specific numerical analyses were asked to benchmark's participants about the dynamical response of this piping specimen, it is worth noticing that the SMART 2013 experimental campaign has shown that RC structural nonlinearities contribute in reducing the dynamic excitation at the lumped mass on the piping. Indeed, the dynamic amplification measured on ZPA at this point with respect to the PGA of the input signal shows an overall multiplicative factor due to RC structure nonlinear behavior, between 0.25 and 0.9 , decreasing with the PGA level. At the same time, the dynamic amplification measured on ZPA calculated at point D of the RC mock-up, in the vicinity of the pipe supports, shows an overall multiplicative factor due to RC structure nonlinear behavior, lying between 0.65 and 1.1 with respect to a linear assumption. This was observed both on experimental and calculated responses by participants. These findings provide arguments justifying the existence of margins in beyond design analysis.

\section{Concluding remarks}

In this paper, the main findings from the international benchmark SMART 2013 carried out from February 2012 to November 2014 and jointly organized by CEA and EDF under the auspices of IAEA within the framework of the research project "Seismic design and best-estimate Methods Assessment for Reinforced concrete buildings subjected to Torsion and nonlinear effect" (SMART) have been presented. The objectives of the benchmark were (i) to quantify the ability of advanced nonlinear approaches to describe the beyond design behavior of a complex RC structure exhibiting coupling torsional/flexural effects, during a realistic seismic scenario, (ii) to quantify the seismic safety margins of a RC mock-up of a representative building designed according to the design rules applicable in the French nuclear industry. All the expected numerical results were referred on the experimental campaign previously performed, whose data and measurements remain available to the public [22]. 42 teams spread out over the world accepted the participation to the benchmark exercise. The teams came from nuclear companies, engineering offices, research centers and higher education institutions pointing out the common interest in the topics addressed in the benchmark. The conclusions that can be drawn of this international benchmark are exposed in the following.

In terms of methodology for calculations, we can quote:

- As observed within the framework of the SMART 2008 benchmark, it can be noticed that the use of advanced nonlinear structural models as best-estimated assessment approaches is shared by the whole earthquake engineering community including universities, research and development institutions and design offices. No participant of SMART 2013 benchmark used equivalent linear approach appearing inappropriate when dealing with the beyond design seismic safety margins assessment. Indeed, the SMART 2013 benchmark has shown that design engineering offices have a satisfactory practice of advanced nonlinear FE models.

- Plate FE models are preferred, for efficiency reasons; other numerical modelling strategies can be seen as research or calibrating approaches.

- Constitutive models for RC sections including damage of concrete are the most appropriate to catch the observed stiffness degradation, though for higher loading levels, other dissipative phenomena have also to be idealized. At this stage, it has been observed that a phenomenon as the steel-concrete bond degradation which plays a major role in the overall behavior of RC sections (e.g. tension stiffening effect) is not yet commonly accounted for in proposed nonlinear structural models for beyond design analyses.

- Often considered as an adjustment variable or sometimes being badly estimated, damping models were better controlled by a higher number of participants. Even though Rayleigh proportional damping remains the most used model, some of the participants have used a modal description of damping which is a step further with respect to SMART 2008 benchmark. This may be explained by the fact that CEA paid a close attention to the identification of modal damping ratios to calibrate numerical approaches. Therefore, noticeable improvements have been made considering both the description of the material dissipation and the way of representing damping at least for the low intensity seismic ground motions.

- Similarly, the calibration of the shaking table FE model, which is dynamically coupled with the mock-up, was decisive to enhance the numerical simulations, first in the linear range, and consequently in the nonlinear range. This observation can be extended to the recommendation of use of ambient noise measurements able to enhance the numerical FE models calibration in real cases of RC structures, to be reassessed.

- It is worth mentioning that a deep joint work has been carried out by CEA and EDF in order to define a seismic loading that is physically consistent with respect to an extreme seismic event that has already occurred in the world. Natural records composed of a main shock and an aftershock for the same couple magnitude-distance were considered, ensuring a certain realism in a spirit of beyond design analysis; their quite large spectral shape ensure an increasing damaging consequence on the RC mock-up within the seismic runs sequence, despite the stiffness degradation. This is a key point that helps emphasizing the relevancy of the comments and conclusions drawn about numerical methodologies devoted to seismic safety margins assessment and beyond design analysis within the framework of SMART 2013 project.

In terms of seismic safety assessment, we can quote:

- The seismic safety margins of the SMART 2013 RC specimen were assessed through two damage indicators by means of blind transient nonlinear dynamic computations. The first indicator is the ISD and is commonly used in the earthquake engineering practices for robustness and performance assessment, especially for regular buildings. The second indicator is the PFS and characterizes the overall degraded structural state, accounting for torsion experienced by complex RC shear wall structures. It is important to highlight that the results coming from both types of damage indicators contributed to demonstrate the existence of seismic safety margins, corroborating experimental observations. It could be interesting to extend this study using a moment-rotation parameter, which is an interesting output to characterize the RC shear wall behavior, in order to discriminate between brittle shear and ductile hinging at the wall footing. From the analyses of both types of results, by comparison with experimental measurements, in particular the mean values obtained from participants, the ISDs have appeared to be slightly underestimated by the numerical models in the $\mathrm{X}$ direction in case of the Northridge main shock seismic sequence, whereas they are quite well described in the Y direction, the most amplified one. On the contrary, the PFSs were quite well predicted by nonlinear models, before and beyond the design level, what is relevant for floor response spectra computations needed for equipment assessment, though the PFS is a less frequently practiced damage indicator.

- This finding has been confirmed by the results coming from the probabilistic vulnerability study. In particular, the fragility curves computations by means of nonlinear time-history analyses and determined using a relevant intensity measure (ASA), in addition to the well-known PGA, have shown a significant median capacity value. Moreover, the ASA intensity measure, [28], which is adapted to degrading stiffness structural behavior, exhibits lower standard deviations than other usual parameters on fragility curves; it has been confirmed that the variability of the seismic motions has the 
most noticeable effect on the capacity variability.

- Nevertheless, the quantification of seismic safety margins cannot dissociate the choice of the damage indicator considered and the relevant intensity measure. Therefore, the question of which damage indicator and which thresholds should be considered must be asked. Furthermore, the lack of numerical models able to predict local quantities in a specific direction points out they are not fully capable to describe torsional effects and rotations, that is to say therefore coupled plane shear and bending of RC sections, when dealing with high intensity seismic loadings.

- However, the existence of the beyond design seismic safety margins exhibited by the SMART 2013 mock-up, representative of a nuclear RC structure that was designed according to the current French nuclear practices, was confirmed by the numerical simulations carried out by the participants. In addition, the numerical quantification of the seismic safety margins was in a quite good agreement with the experimental values, considering the numerous variability of modelling assumptions.

In terms of state of practice and development of nonlinear numerical modelling, we can observe:

- We have to emphasize the already significant work carried out to make the numerical models more reliable. Especially, one can notice that the solution algorithms used were efficient, the calibration and the identification methods considered by the participants were relevant. Most of the numerical approaches could solve the highly nonlinear transient dynamic problem in a robust way, what is a necessary condition to deal with probabilistic vulnerability studies. It is worth noticing their ability to accurately predict structural quantities such as peak frequency shifts coming from nonlinear behavior of RC structural elements.

- The improvements of the best-estimate approaches to make meaningful seismic assessments of complex nuclear RC structure have clearly been highlighted, and, despite the scatter of results partially inherent in the voluntary nature of participations, such benchmark exercise contributes to be enhance the reliability of their implementation in the engineering practice. This trend is in agreement with the recommendations from IAEA that promotes a more systematic use of nonlinear models.

- Benchmark exercise, gathering several participants, has shown that probabilistic seismic safety assessment, accounting for uncertainties on the ground motions and on the material parameters, can be implemented including fragility curve calculations from nonlinear time-history analyses on critical buildings. It can reasonably become a common practice in engineering offices, provided that the issue, in particular avoiding some overestimation of the seismic fragility, can balance the significant amount of computing time, in order to update seismic capacities assessment according to new probabilistic seismic hazard analyses. Nevertheless, it is emphasized the need of better consistency in the choice of the ground motion dataset with the specific site seismic hazard (and the associated intensity measures) and the structural behavior.

- However, SMART 2013 benchmark results have shown that further developments are needed to make nonlinear models more robust and reliable in assessing local quantities.

- This conclusion is in agreement with the main findings made within the framework of CEOS.fr French national research program [32] mainly founded by EDF and the MEFISTO research program financially supported by the French National Research Agency.

The future step will consist in providing structural engineers with more accurate recommendations and guidelines on the way of using best-estimate assessment methodologies to ensure a certain confidence level in the outcome results. In that goal, the usefulness of such numerical benchmark based on well-documented experimental measurements is well established, aiming at consolidating the engineer judgment and reducing the scatter of results, and finally at qualifying advanced engineering practices. Finally, this benchmark has also allowed identifying several topics on which further investigations seem to be necessary. For instance, how to reduce the discrepancies between experiments and simulations, how to enhance the control of uncertainties and the model calibration, in the analysis of the interaction between slab and structural walls, etc. These works should clearly help to assess the seismic safety margins of a given nuclear plant or any other industrial facility in a more realistic way.

\section{Acknowledgements}

The Authors would like to thank all the institutions which participated in the SMART 2013 project and in the International Benchmark for the huge work carried out. CEA and EDF are gratefully thanked for material and financial supports. The work reported in this paper has also been supported by the SEISM Institute (http://www.institut-seism.fr).

\section{Appendix A. Appendix}

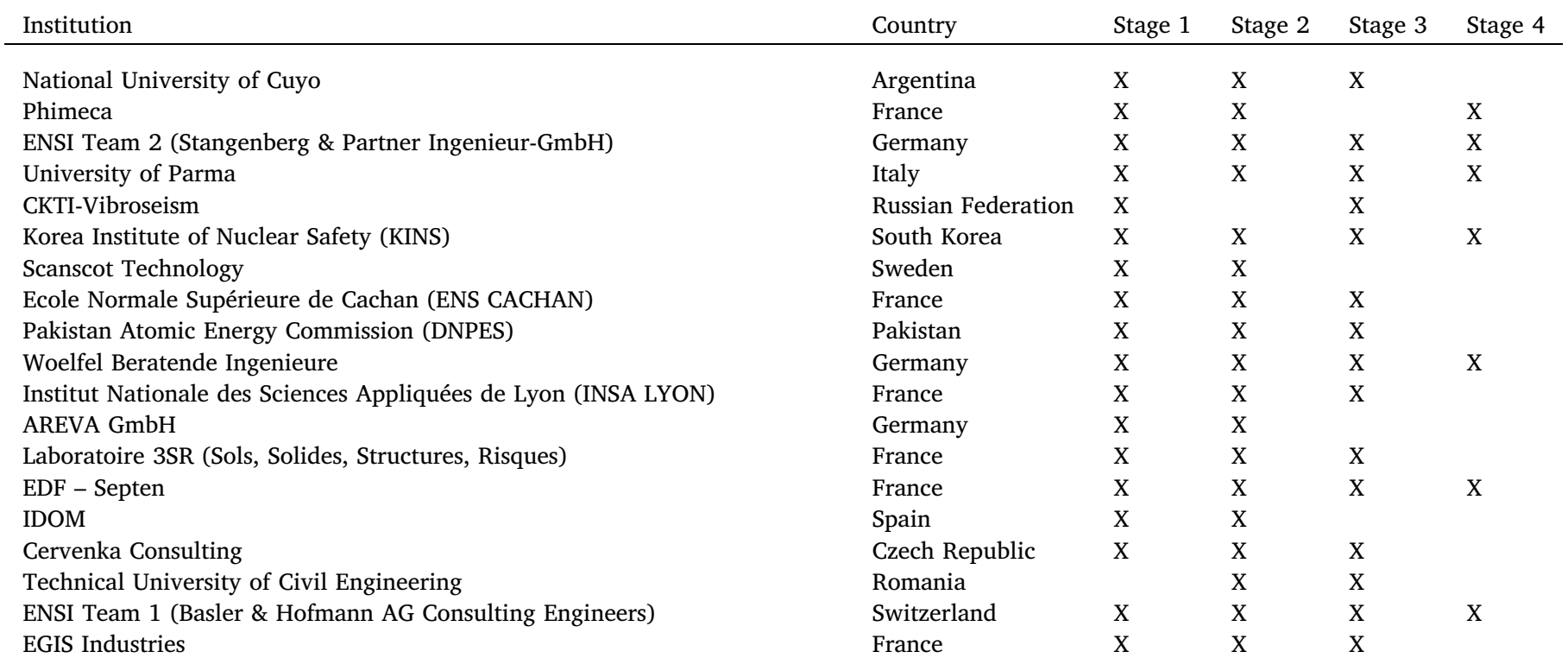


Faculty of Civil Engineering

China Guangdong Nuclear Power Design Company

Nagoya University

Middle-East Technical University

University of Houston

State Nuclear Electric Power PlanningDesign \& Research Institute (SNPDRI)

Computational Engineering and Structures (CES)

Alyotech Technologies

Technical University "Gheorghe Asachi"

Swissnuclear

Rene Lagos Engineers SAC

Ecole Polytechnique Fédérale de Lausanne

PRINCIPIA

Autodesk

Laboratório Nacional de Engenharia Civil (LNEC)

TNO DIANA BV

ATR Ingenierie

Géodynamique et Structure (GDS)

SDA-engineering $\mathrm{GmbH}$

Fortum Power and Heat Oy

Numerical Engineering and Consulting Services (NECS)

University of California, Berkeley (UCB)

$\begin{array}{llll}\text { Macedonia } & & \mathrm{X} & \mathrm{X} \\ \text { China } & \mathrm{X} & \mathrm{X} & \mathrm{X} \\ \text { Japan } & \mathrm{X} & \mathrm{X} & \mathrm{X} \\ \text { Turkey } & \mathrm{X} & & \\ \text { USA } & \mathrm{X} & & \\ \text { China } & \mathrm{X} & & \\ \text { France } & \mathrm{X} & \mathrm{X} & \mathrm{X} \\ \text { France } & \mathrm{X} & & \\ \text { Romania } & \mathrm{X} & \mathrm{X} & \mathrm{X} \\ \text { Switzerland } & \mathrm{X} & \mathrm{X} & \mathrm{X} \\ \text { Chile } & \mathrm{X} & & \\ \text { Switzerland } & \mathrm{X} & \mathrm{X} & \mathrm{X} \\ \text { Spain } & \mathrm{X} & \mathrm{X} & \mathrm{X} \\ \text { France } & \mathrm{X} & \mathrm{X} & \mathrm{X} \\ \text { Portugal } & \mathrm{X} & \mathrm{X} & \\ \text { The Netherlands } & \mathrm{X} & \mathrm{X} & \mathrm{X} \\ \text { France } & \mathrm{X} & \mathrm{X} & \mathrm{X} \\ \text { France } & \mathrm{X} & \mathrm{X} & \\ \text { Germany } & & \mathrm{X} & \\ \text { Finland } & \mathrm{X} & \mathrm{X} & \mathrm{X} \\ \text { France } & \mathrm{X} & \mathrm{X} & \mathrm{X} \\ \text { USA } & \mathrm{X} & & \end{array}$

$\mathrm{X}$

$\mathrm{X}$

$x$

$x$

$\mathrm{X}$

$\mathrm{X}$

$\mathrm{X}$

$\mathrm{X}$

$\mathrm{X}$

$\mathrm{X}$

$\mathrm{X}$

$\mathrm{X}$

$\mathrm{X}$

\section{References}

[1] Hasegawa T, Kumagai H, Irino K, Rots JG, Feenstra PH. Seismic analysis of RC shear wall. In: Proceedings fourteenth international conference on structural mechanics in reactor technology. HKW/13; 1997.

[2] Kitada Y, Akino K, Terada K, Aoyama H, Miller A. Report on seismic shear wall international standard problem organized by OECD/NEA/CSNI. In: Proceedings fourteenth international conference on structural mechanics in reactor technology. HKW/1; 1997.

[3] Minami T, Nishikawa T, Yoshimura M, Ono H. Study on the dynamic inelastic behavior of seismic shear walls of the reactor building. In: Proceedings fourteenth international conference on structural mechanics in reactor technology. HKW/11; 1997.

[4] Ueda M, Seya H, Ohmiya Y, Taniguchi H, Kambayashi A. Nonlinear analysis of RC shear wall shaking table test. In: Proceedings fourteenth international conference on structural mechanics in reactor technology. HKW/16; 1997.

[5] Ile N, Reynouard JM. Nonlinear analysis of reinforced concrete shear wall under earthquake loading. J Earthquake Eng 2000;4(2):183-213.

[6] Bisch Ph, Coin A. The CAMUS research programme. In: Proceedings of the 11th european conference on earthquake engineering, 4-8th September 1998, Paris, France, Balkema, Rotterdam; 1998.

[7] Queval JC, Combescure D, Sollogoub P, Coin A, Mazars J. CAMUS experimental program. In: Plane tests of 1/3rd scaled R/C bearing walls. In: Proceedings of the 11th European conference on earthquake engineering, 4-8th September 1998, Paris, France, Balkema, Rotterdam; 1998.

[8] Labbé P, Altinyollar A. Conclusions of an IAEA-JRC research project on the safety significance of near-field seismic motions. Nucl Eng Des 2011;241(5):1842-56.

[9] Panagiotou M, Restrepo JI, Conte JP. Shake-table test of a full-scale 7-story building slice. Phase I: Rectangular wall. J Struct Eng 2011;137(6):691-704.

[10] Waugh JD, Sritharan S. Lessons learned from seismic analysis of a seven-story concrete test building. J Earthquake Eng 2010;14(3):448-69.

[11] Martinelli P, Filippou F. Simulation of the shaking table test of a seven-story shear wall building. Earthquake Eng Struct Dyn 2009;38(5):587-607.

[12] Grange S, Kotronis P, Mazars J. Numerical modelling of the seismic behavior of a 7story building: NEES benchmark. Mater Struct 2009;42(10):1433-42.

[13] Kelly T. A blind prediction test of nonlinear analysis procedures for reinforced concrete shear walls. NZSEE Bull 2007;40(3):142-59.

[14] Simos N, Hofmayer C-H. Experimental Studies of Reinforced Concrete Structures Under Multi-Directional Earthquakes and Design Implications. July 2013. NUREG/ CR-7119; 2013.

[15] Richard B, Martinelli P, Voldoire F, Chaudat T, Abouri S, Bonfils N. SMART 2008: overview, synthesis and lessons learnt from the International Benchmark. Eng Struct 2016;106:166-78.

[16] Juster-Lermitte S, Chaudat Th, Courtois A. SMART 2008 project experimental tests of a reinforced concrete building subjected to torsion. In: Proceedings 20th international conference on structural mechanics in reactor technology. Paper Div.V1700; 2009.
[17] Richard B, Martinelli P, Voldoire F, Corus M, Chaudat T, Abouri S, et al. SMART 2008: shaking table tests on an asymmetrical reinforced concrete structure and seismic margins assessment. Eng Struct 2015;105:48-61.

[18] Rapport DES. Proposition de modification de la règle fondamentale de sûreté 1.2. c relative à la détermination des mouvements sismiques à prendre en compte pour la sûreté des tranches nucléaires comportant un réacteur à eau sous pression, applicable à l'ensemble des installations nucléaires de base. Institut de Protection et de Sûreté Nucléaire; 1998.

[19] Gupta, O, Lacoste AC. Prise en compte du risque sismique à la conception des ouvrages de génie civil d'installations nucléaire de base à l'exception des stockages à long terme des déchets radioactifs. Guide de l'Autorité de Sûreté Nucléaire. ASN/ GUIDE/2/01. Autorité de Sûreté Nucléaire; 2006.

[20] Richard B, Cherubini S, Voldoire F, Charbonnel PE, Chaudat T, Abouri S, et al. SMART 2013: experimental and numerical assessment of the dynamic behavior by shaking table tests of an asymmetrical reinforced concrete structure subjected to high intensity ground motions. Eng Struct 2016;109:99-116.

[21] Field EH, Johnson PA, Beresnev IA, Zeng Y. Nonlinear ground-motion amplification by sediments during the 1994 Northridge earthquake. Nature 1997:390(6660):599-602.

[22] SMART 2013 Website. <https://www.institut-seism.fr/en/projects/smart/>.

[23] Menegotto M, Pinto PE. Method of analysis for cyclically loaded RC plane frames including changes in geometry and nonelastic behavior of elements under combined normal force and bending. In: Proc. IABSE symposium, Lisbon, Portugal; 1973.

[24] Markovic D, Koechlin P, Voldoire F. Reinforced concrete structures under extreme loading: Stress resultant Global Reinforced Concrete Models (GLRC). Greece: ECCOMAS COMPDYN; 2007.

[25] Heidebrecht AC, Naumoski ND. Development and application of a displacementbased design approach for moment-resisting frame structures. In: Fajfar P, Krawinkler H, editors, Seismic design methodologies for the next generation of codes, Rotterdam: AA Balkema; 1997. p. 217-28.

[26] FEMA 273. NEHRP Guidelines for the seismic rehabilitation of buildings. Federal Emergency Management Agency; 1997.

[27] Zentner I. Numerical computation of fragility curves for NPP equipment. Nucl Eng Des 2010;240(6):1614-21.

[28] De Biasio M, Grange S, Dufour F, Allain F, Petre-Lazar I. A simple and efficient intensity measure accounting for non-linear behavior of structures. Earthquake Spectra 2014;30(4):1403-26.

[29] Borst RD, Remmers JJ, Needleman A, Abellan MA. Discrete vs smeared crack models for concrete fracture: bridging the gap. Int J Numer Anal Meth Geomech 2004;28(7-8):583-607.

[30] Sukumar N, Moës N, Moran B, Belytschko T. Extended finite element method for three-dimensional crack modelling. Int J Numer Meth Eng 2000;48(11):1549-70.

[31] Oliver J, Huespe AE, Pulido MDG, Chaves E. From continuum mechanics to fracture mechanics: the strong discontinuity approach. Eng Fract Mech 2002;69(2):113-36.

[32] Rospars C, Chauvel D. CEOS.fr experimental program and reference specimen tests results. Eur J Environ Civil Eng 2014;18(7):738-53. 